U.S. Department

of Transportation

National Highway

Traffic Safety

Administration

DOTHS 808091

February 1994

Focus Group Report

\title{
Responses of Women and Men to Traffic Safety Messages: A Qualitative Report
}


This publication is distributed by the U.S. Department of Transportation, National Highway Traffic Safety Administration, in the interest of information exchange. The opinions, findings and conclusions expressed in this publication are those of the author(s) and not necessarily those of the Department of Transportation or the National Highway Traffic Safety Administration. The United States Government assumes no liability for its contents or use thereof. If trade or manufacturers' name or products are mentioned, it is because they are considered essential to the object of the publication and should not be construed as an endorsement. The United States Government does not endorse products or manufacturers. 


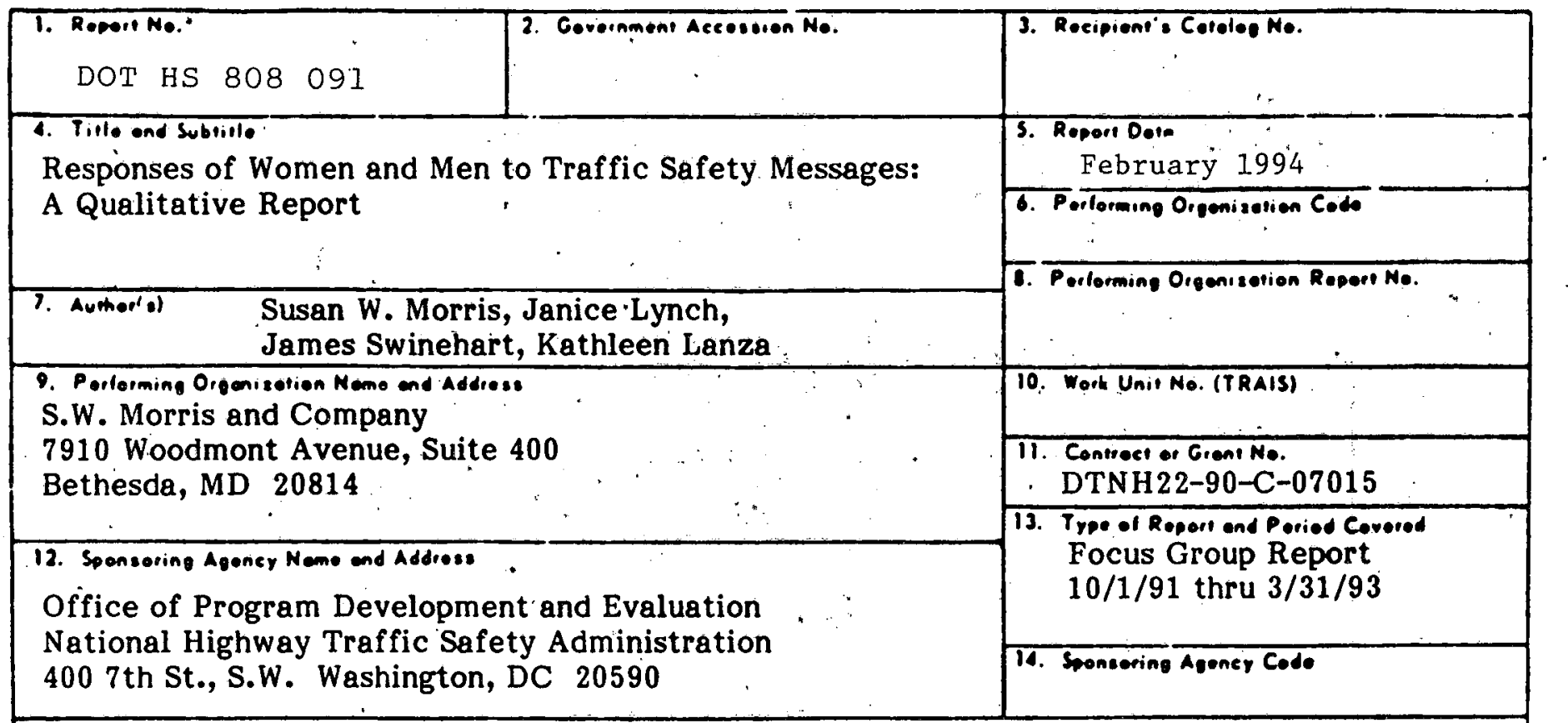

15. Supplementery Hotes

The Contracting Officer's Technical Representative on this contract was Douglas Gurin.

\section{Abstrect}

More information about receptivity to traffic safety communications is needed to develop effective media campaigns for women. This project sought to obtain such information through (1) a review of literature on gender differences in response to traffic safety and health-related messages and (2) interviews with groups of men and women to evaluate their responses to selected traffic safety public service announcements (PSAs).

S.W. Morris \& Co. conducted a review of the relevant research and talked with a number of experts on this subject. The review revealed that few data are available to characterize women who are involved in crashes or to describe their responses to advertising. However, the background review yielded information on gender-based issues that should prove useful in the design of public information and education programs for women.

Eight focus groups involving a total of 28 men and 32 women, aged 25-59, were conducted in 1992. Participants discussed their driving habits and attitudes and how these had changed in recent years, as well as traffic violations committed by other drivers and by themselves.' They älso gave detailed reactions to seven televised PSAs, which dealt with three topics (drinking and driving, speed compliance, and safety belt usage) by conveying various motivational themes (enforcement risks, physical injury, fatality risk, normative appeal, financial cost, and personal responsibility). Although there were several similarities between the responses of men and women, more often than not their reactions to driving situations and safety advertising were different. As compared with male participants, some female participants tended to drive more aggressively; they often noted the stress of driving with children in the car; older women mentioned the problem of reduced night vision; female participants generally responded more favorably to emotional appeals in advertising, were less accepting of humor, were less concerned about production values, objected less to exhortative or authoritarian appeals, were more likely to perceive information as relevant to their family or friends, and were more sensitive to the potential for negative stereotyping in portrayals of women as poor drivers.

The report includes a number of specific recommendations regarding future qualitative and quantitative studies.

17. Kay word" Drivers, male, female, men," women, crashes, gender, sex, gender differences, similarities, traffic safety, public service announcements, traffic safety message, driving habits, drinking and driving, speeding, speed compliance, safety belts, seatbelts, public information and education campaigns, perceptions.

\footnotetext{
19. Security Clecoit. (ol mie resori)
}

20. Security Clecesil. (of this popol

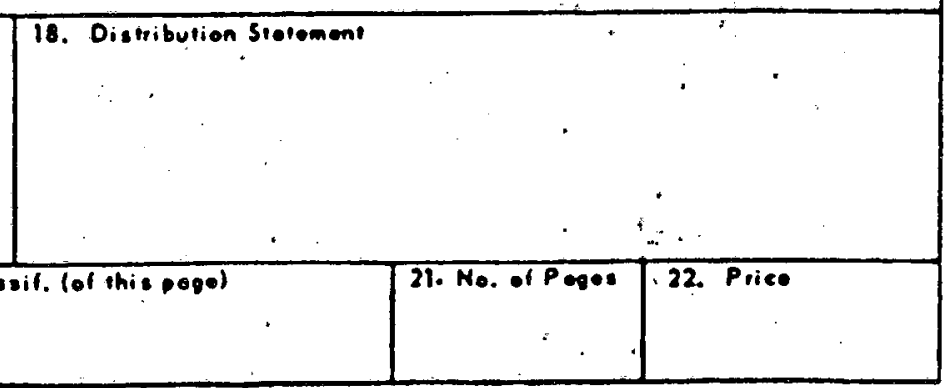




\section{Table of Contents}

Executive Summary $\ldots \ldots \ldots \ldots \ldots \ldots \ldots \ldots \ldots \ldots \ldots \ldots \ldots$ ix

I. Background $\ldots \ldots \ldots \ldots \ldots \ldots \ldots \ldots \ldots \ldots \ldots \ldots$

A. Review of Current Knowledge About Gender Targeting . . . . . . . . 1

1.Traffic Safety Communications . . . . . . . . . . . . . . . . . . 2

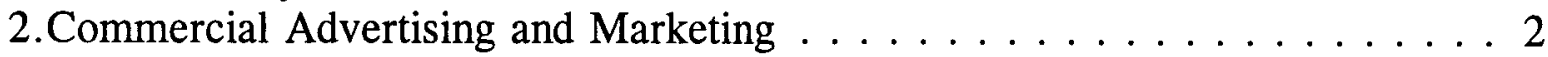

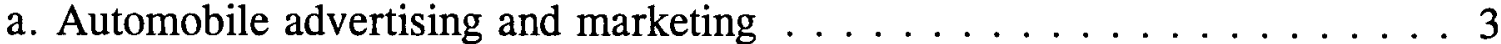

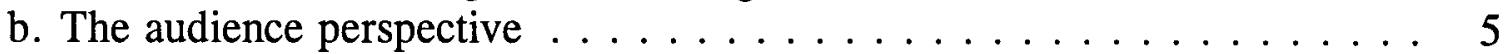

3. Public Health Communications . . . . . . . . . . . . . . . 5

4. Academia . . . . . . . . . . . . . . . . . . 7

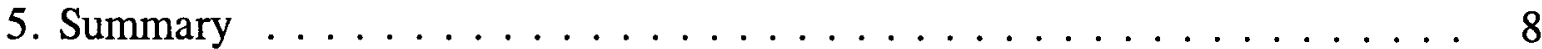

II. Methodology $\ldots \ldots \ldots \ldots \ldots \ldots \ldots \ldots \ldots \ldots \ldots \ldots \ldots$

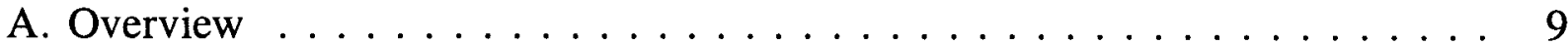

B. Participant Selection . . . . . . . . . . . . . . . . . . 9

1. The Case for Talking to Men and Women .............. 9

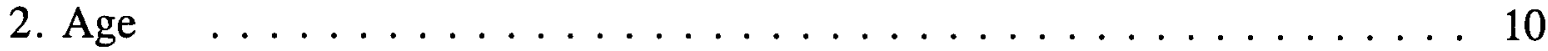

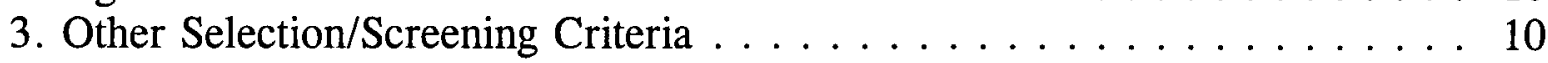

C. Recruitment . . . . . . . . . . . . . . . . . . . . . 11

1. Participant Characteristics . . . . . . . . . . . . . . . . 11

2. Location . . . . . . . . . . . . . . . . . . . . . . . 12

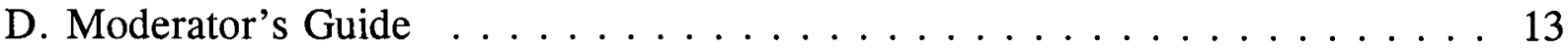

E. Test Materials Selection . . . . . . . . . . . . . . . . . . . . . . 14

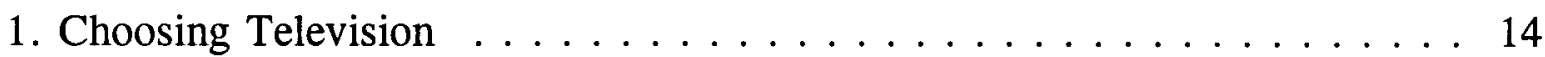

2. Narrowing the Field $\ldots \ldots \ldots \ldots \ldots \ldots \ldots \ldots$

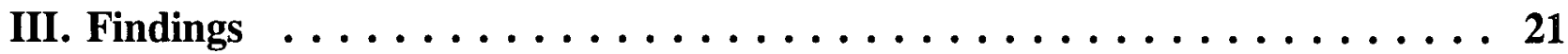

A. Driving Attitudes and Habits . . . . . . . . . . . . . 21

B. Recollections of Televised PSAs . . . . . . . . . . . . . . . . . 25

C. Reactions to PSAs Shown in Focus Groups . . . . . . . . . . . . . 26

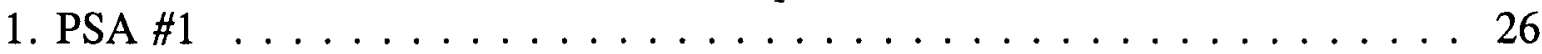

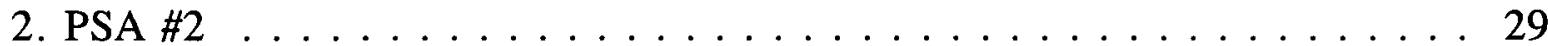

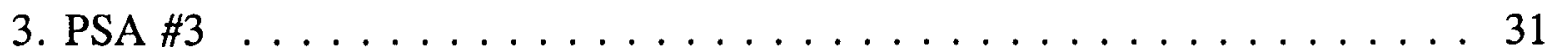

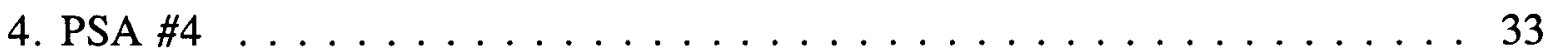

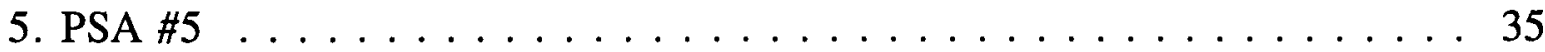

6. PSA \#6 . . . . . . . . . . . . . . . . . . . . 39

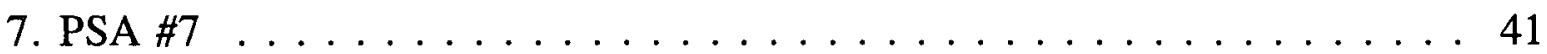


D. Participant Suggestions for Appealing to Men and Women . . . . . . . . . 43

1. Use Realistic Settings and Common/Typical Situations . . . . . . . . . . . 43

2. Use Persons of Appropriate Gender and Age . . . . . . . . . . . . . 43

3. Demonstrate Effective Interventions and Other Actions . . . . . . . . . . . 44

E. Communications Styles and Behavior . . . . . . . . . . . . . . . . 44

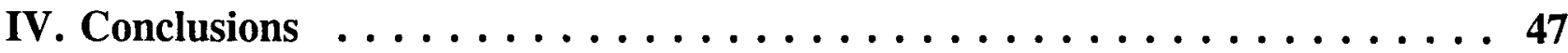

A. Similarities Between Men and Women . . . . . . . . . . . . . . . 47

1. In terms of driving attitudes and habits, men and women

in the groups . . . . . . . . . . . . . . . . . . . 47

a. Were concerned about their safety in automobiles and believe it may be compromised by other drivers . . . . . . . . . 47

b. Sometimes found driving relaxing, an opportunity to

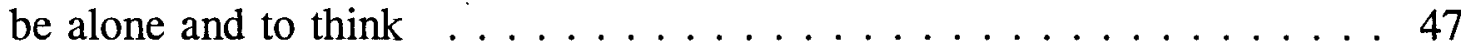

c. Drive more cautiously when children are in the car . . . . . . . . . 48

d. Admitted to venting the day's stresses and frustrations

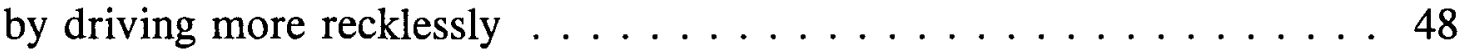

2. Discussions about traffic safety PSAs revealed that men and women in the groups ... . . . . . . . . . . . . 48

a. Were aware of advertising strategies and marketing techniques . . . . . . 48

b. Said they would like specific advice on how to deal with certain situations, especially with regard to influencing friends' unsafe driving behaviors . . . . . . . . . . . . . . 48

c. Felt the age of the presenter in a PSA should be close

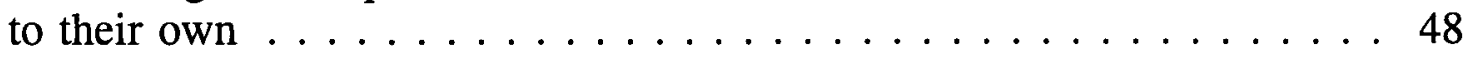

d. Wanted to see realism and personal relevance in PSAs about traffic safety . . . . . . . . . . . . . . . . . . . . . . . . . 49

e. Responded to appeals that hit drivers in the wallet or the pocketbook. . . . . . . . . . . . . . . . . . . . . 49

B. Differences Between Men and Women . . . . . . . . . . . . . . . . . 49

1. In terms of driving attitudes and habits . . . . . . . . . . . . . . . 49

a. Many younger women described themselves as aggressive or assertive drivers, sometimes engaging in direct confrontation with other drivers .

b. Women often cited the stress of driving with children, although men rarely mentioned this . . . . . . . . . . . . . . . . 49

c. Older women were more attuned than older men to the effects of the aging process on their driving skills $\ldots \ldots \ldots \ldots \ldots$ 
2. In terms of the specific PSAs presented, the following differences emerged

a. Women in the groups responded more favorably to emotional appeals than did men . . . . . . . . . . . . . . . 50

b. Female participants felt humorous approaches detracted from the seriousness of the material being presented while many of the male participants preferred this approach .................... 50

c. Female participants generally had no objections to PSAs with an explicit exhortation to take a given action, while most of the men found this

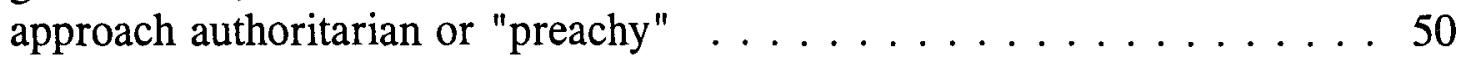

d. The female participants were not as concerned about production values as the men in the groups . . . . . . . . . 51

e. Women were more likely to say they would watch an entire PSA, while many men said they would have used the television's remote control to change the channel . . . . . . . . 51

f. Women perceived PSA information as relevant to others in their lives like parents, children, friends, as well as to themselves . . . . . . . . . . . . . . . . . . . 51

g. Women derived meaning from every PSA regardless of its target audience or the sex of the spokesperson . . . . . . . . . 51

h. Women were sensitive to the potential for negative gender stereotyping in traffic safety PSAs.

V. Recommendations ....................... 53

A. Recommendations Regarding Qualitative Studies . . . . . . . . . . . 53

1. Conduct Additional Background Reviews . . . . . . . . . . . 53

2. Conduct Gender-Based Focus Groups With a Wider Range of Respondents . . . . . . . . . . . . . . . . . . . . . 54

a. Young drivers . . . . . . . . . . . . . . . . . . 54

b. Older drivers . . . . . . . . . . . . . . . . . . . . . 54

c. Women who have been involved in crashes . . . . . . . . . . . 54

d. Women who are at risk for crash involvement . . . . . . . . . . 54

3. Collect Information on Receptivity of At-Risk Populations . . . . . . . . . 55 
4. Additional Research . . . . . . . . . . . . . . . . . . . . . . 55

a. Evaluate gender-based differences in response to non-PSA materials used in other public sector and commercial campaigns. . . . . . . . . . . . . . . . . 55

b. Examine gender differences in perceptions of common traffic safety vocabulary $\ldots \ldots \ldots \ldots \ldots \ldots \ldots$

c. Explore more fully other potentially effective ways of reaching women with traffic safety messages . . . . . . . . . . 56

d. Explore other safety topics, themes, and approaches . . . . . . . . 56

e. Examine gender perceptions using carefully tailored messages and production . . . . . . . . . . . . . . 56

B. Recommendations Regarding Quantitative Studies . . . . . . . . . . . . . 57

1. Collect Crash Trend Data . . . . . . . . . . . . . . . . . . . . 57

a. Characteristics of single- and multi-vehicle crashes and the types of crashes and cars involved . . . . . . . . . . 57

b. Characteristics of drivers involved in crashes, including marital status, employment status, prior traffic violations, and socioeconomic variables . . . . . . . . . . . . . 57

c. Elements contributing to the crash . . . . . . . . . . . . 57

d. Crash injuries sustained, including their nature and extent of physical and psychological injuries, prognosis for long-term recovery, and financial costs . . . . . . . . . . . 57

e. Insurance coverage (or non-coverage), claims filed, and claims disposition . . . . . . . . . . . . . . 57

2. Estimate Message Receptivity _. . . . . . . . . . . . . . . . 58

3. Plan for Gender Analyses . . . . . . . . . . . . . . . . . 58

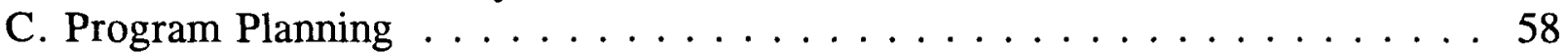

1. Target Audiences With Information Delivered By Age-Appropriate Persons . . . . . . . . . . . . . . . . . . . 59

2. Show Persons Engaged in Real-Life Day-to-Day Situations . . . . . . . 59

3. Educate Women About Their Risk of Involvement in Serious Crashes . . . . . . . . . . . . . . . . . . . . . . . . . . 59

4. Develop Messages That Address the Needs and Problems of Women Drivers . . . . . . . . . . . . . . . . . . . . . . . . . 59

5. Avoid Perpetuating Unfounded Stereotypes About Women as Poor Drivers . . . . . . . . . . . . . . . . . . . . . . . 59

D. Additional Study . . . . . . . . . . . . . . . . . . . . . 60

1. Determine Effective Communications Channels to Reach At-Risk Drivers . . . . . . . . . . . . . . . . . . . . . . 60

2. Conduct Studies of Innovative Communications Channels . . . . . . . 60 


\section{Appendices}

Appendix A Bibliography $\ldots \ldots \ldots \ldots \ldots \ldots \ldots \ldots \ldots \ldots$ A-1

Appendix B Experts and Consultants $\ldots \ldots \ldots \ldots \ldots \ldots \ldots \ldots \ldots \ldots \ldots$ B-1

Appendix B1 List of Experts Consulted or Interviewed . . . . . . . . . B-2

Appendix B2 Participảnt List: General Motors Corporation Meeting ... . B-4

Appendix B3 Participant List: Chrysler Corporation Meeting . . . . . . . . B-5

Appendix B4 Participant List: Ford Motor Company Meeting . . . . . . B-6

Appendix C Research and Programs Analyzed for Background Review ... C-1

Appendix C1 Table A: Review of Commercial Sector . . . . . . . . . C C-2

Appendix C2 Table B: Review of Public Sector . . . . . . . . . . . C-3

Appendix C3 Table C: Review of Academia . . . . . . . . . . . C-4

Appendix D Focus Group Materials $\ldots \ldots \ldots \ldots \ldots \ldots \ldots \ldots \ldots$ D-1

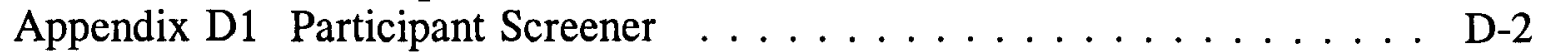

Appendix D2 Moderator's Guide ................ . D-6

Appendix D3 Sample PSA Rating Form . . . . . . . . . . . . . D-10

Appendix D4 Participant Information Sheet . . . . . . . . . . . D-11

Appendix D5 Participant Information Sheet/

Selected Response Tallies . . . . . . . . . . . . . D-14

\section{List of Tables}

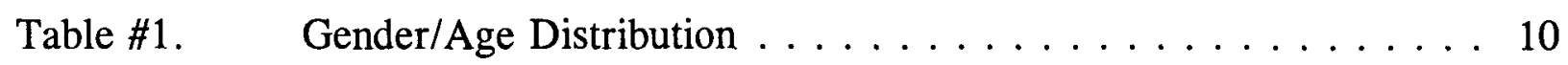

Table \#2. Participant Demographic Profiles $\ldots \ldots \ldots \ldots 12$

Table \#3. Message Themes and Highway Safety Topics of Television PSAs Considered for Use in Focus Groups . . . . . . . . . . . . 17

Table \#4. $\quad$ Recommended PSAs for Gender Focus Groups . . . . . . . . . . 19

Table \#5. Characteristics of Chosen PSAs by Theme . . . . . . . 20 


\section{Executive Summary}

\section{Background}

The National Highway Traffic Safety Administration (NHTSA) conducts a range of public information and education (PI\&E) programs designed to educate drivers about highway and traffic safety issues. Years of safety messages aimed at the general public and recent messages targeted at male drivers ages 18 to 25 have helped lower the nation's fatality rates to their lowest historical levels. NHTSA also wants to examine how best to reach women drivers with safety messages.

\section{Methodology}

\section{Overview}

A background review of past studies on gender-response differences to traffic safety messages, as well as interviews with experts, yielded surprisingly little information. In fact, it was found that gender-based differences have not been widely studied in most public health education campaigns and non-proprietary advertising research.

In late 1992, eight focus groups dealing with perceptions of traffic safety messages were conducted. The groups differed by gender (four groups of men, four of women) and age (four groups of persons aged 25 to 39, four of persons aged 40 to 59). Most of the time in the sessions was spent discussing the men's and women's reactions to several safety-motivating television public service announcements (PSAs) on themes (such as enforcement or fatality risk) addressing three highway safety topics: drunk driving, speeding, and non-use of seat belts.

\section{Participant Selection}

A total of 28 men and 32 women participated in the groups, which were held in suburban Washington, DC. Participants had to be licensed drivers who annually drove at least 10,000 miles (for men) and 7,000 miles for women. In the absence of problem-revealing crash data, characteristics of those in the groups included a mix of marital status, dependents, size of vehicles driven, and educational levels. 
problem-revealing crash data, characteristics of those in the groups included a mix of marital status, dependents, size of vehicles driven, and educational levels.

\section{Discussion Sequence}

Participants were asked several questions regarding general driving issues and traffic safety. They were then asked to recall any traffic safety messages they could and why those messages were memorable.

To ascertain whether men and women perceive traffic safety messages differently, several TV PSAs on safety topics were shown in each group. Participants filled out rating forms, then commented on such things as what they liked or disliked, the main message, and whether they thought the ad would work better with men or with women.

\section{Test Materials Selection}

Television PSAs were chosen as the materials to be shown in part because in 30 seconds they can provide considerable stimulus for discussion within focus groups (30-second radio PSAs are typically less involving). Most print materials contain more information but take longer to read and digest. Using materials from only one medium helped to keep the focus on reactions to the themes presented rather than on media differences.

Pre-existing PSAs were placed in categories combining the three safety topics with six safety-motivating themes or appeals.

The following themes were used in the PSAs shown:

- Enforcement risks.

- Physical injury to self or to others as a result of negligence or breaking a traffic law.

- Fatality risks to self or to others.

- Endorsement or normative appeal: implies that "everybody's doing it" or "there's something wrong with you if you don't do it."

- Financial costs: depicts how disobeying a law can result in financial loss through a fine or higher insurance premiums. 
- Personal/moral/social responsibility: emphasizes making a specific intervention to stop unsafe driving because it is the responsible thing to do.

More than 250 PSAs were eliminated either because they were outdated, lacked production quality, or did not meet other evaluation criteria. Six PSAs were chosen to be shown in the first groups; a seventh was added for later sessions.

\section{Findings}

The study findings are based on discussions concerning driving attitudes and habits, the PSA themes, communications styles, and suggestions for tailoring safety messages for men and women.

Generalizations from the focus groups should be regarded as tentative, since reactions came from a small, non-statistically chosen population. Reactions were shaped by the interaction among the safety topics, the themes/appeals, and various production techniques.

\section{Driving Attitudes and Habits}

Drivers described a range of attitudes about driving, from a sense of frustration at external problems (e.g., highway construction, discourteous drivers, increased traffic congestion) to a sense of pleasure in driving alone. Younger women were least likely to consider driving a pleasure; many reported that they have rearranged their work schedules to avoid driving during rush hours. Others stated driving is simply a means to an end, an activity they would avoid if they could.

Temperament, rather than gender, seemed to be the critical factor governing how stress affects people's driving. Some men and women said they don't let things get to them, while others reported that a stressful day at work sometimes leads to risktaking behind the wheel.

All drivers described a range of traffic violations they have seen other drivers commit, especially speeding, passing illegally, running red lights or stop signs, and not using turn signals. When asked to describe their own traffic offenses, people primarily cited speeding and failure to always wear seat belts.

In terms of similarities, men and women in the groups: 
xii

- Were concerned about their safety in cars and believe it may be compromised by other drivers.

- Sometimes found driving relaxing, an opportunity to be alone and to think.

- Said they drive more cautiously when children are in the car.

- Admitted to venting the day's stresses and frustrations sometimes by driving more recklessly.

These differences emerged:

- Many younger women described themselves as aggressive or assertive drivers, sometimes engaging in direct confrontation with other drivers.

- Women often cited the stress of driving with children, although men rarely mentioned this.

- Older women talked more about the effects of aging on their driving skills than older men.

\section{Recall of Traffic Safety PSAs}

In several groups, very few people were able to describe any PSAs they could remember having seen or heard, although many participants described highway traffic signs with messages about wearing seat belts or not speeding. The PSAs most often mentioned were those featuring Vince and Larry, as well as PSAs concerned with drinking and driving, such as the "Friends Don't Let Friends Drive Drunk" and designated driver campaigns.

Asked why they recalled certain PSAs, men pointed to the humorous approach taken by the Vince and Larry campaign. Women recalled PSAs they characterized as being tragic or that featured the consequences of certain actions. 


\section{Reactions to Selected PSAs}

The study report describes the PSA response similarities and differences between men and women. Reactions varied greatly from one PSA to the other; men and women made essentially the same comments in some cases, while in others their reactions diverged sharply.

As for similarities, both men and women:

- Were fairly knowledgeable about advertising and marketing strategies.

- Said they would like specific advice on how to deal with certain situations, especially with regard to influencing friends' unsafe driving.

- Felt the age of the presenter in a PSA should be close to their own.

- Wanted to see realism and personal relevance in traffic safety PSAs.

- Felt that the threat of financial costs (fines, insurance) was a potentially effective appeal.

These differences emerged:

- Women responded more favorably to emotional appeals than men.

- Female participants felt humorous approaches detracted from the seriousness of the material presented, while many men preferred this approach.

- Women generally had no objections to PSAs with an explicit exhortation to take a given action, while most of the men found this approach authoritarian or "preachy."

- The female participants were not as concerned about production values as were men.

- Women were more likely to say they would watch an entire PSA, while many men said they would change the channel if they disliked the first few seconds. 
- Women more often than men perceived PSA information as relevant to others in their lives (parents, children, friends) as well as to themselves.

- Women said the gender of the star or narrator was not important in communicating a safety message.

- Women were sensitive to the potential for negative gender-stereotyping in traffic safety PSAs.

\section{Participant Suggestions for Appealing to Men and Women}

When asked how producers could improve the effectiveness of traffic safety PSAs, participants suggested:

- Using realistic settings and common situations that are relevant to the target audience.

- Using persons of appropriate age.

- Demonstrating effective interventions and other realistic actions to influence others.

\section{Recommendations}

Recommendations for future qualitative and quantitative research stem from information collected and the background review. The lack of background data led staff to suggest future activities to obtain additional information on gender-related response differences. Men and women should be included in both qualitative and quantitative studies on this topic.

\section{Recommendations Regarding Qualitative Studies}

- Conduct additional background reviews in other areas of consumer risk taking, such as insurance, banking, retirement planning, financial investment, and credit card acquisition.

- Conduct gender-based focus groups with a wider range of respondents: both younger and older drivers than the participants in this study, and 
drivers who have been involved in crashes or who are at risk for crash involvement.

- Collect information on receptivity of, at-risk, populations e.g., males and females with specific psychological, social, or economic problems.

\section{Additional Research}

- Evaluate gender-based differences in response to non-PSA materials used in other public sector and commercial campaigns.

- Examine gender differences in perceptions of common traffic safety vocabulary, e.g., "speeding," "drunk driving."

- Explore more fully other potentially effective channels of communication for reaching women with traffic safety messages, e.g., Departments of Motor Vehicles, automotive dealerships, videos for new car owners.

- Explore innovative channels of communication to reach at-risk drivers.

- Explore other safety topics than the three chosen for this study.

- Examine perceptions of new materials designed to appeal specifically to women, men, or both women and men.

\section{Recommendations Regarding Quantitative Studies}

- Collect crash trend data. Beyond the numbers that show age and sex trends in crash fatalities, information is needed on these other variables that would tell a more complete story about male and female crash involvement and consequences:

Characteristics of single- and multi-vehicle crashes and the types of crashes and cars involved.

Characteristics of drivers involved in crashes, including marital status, employment status, prior traffic violations, and socioeconomic variables.

Elements contributing to the crash.

Medical consequences, initially and among survivors. 
xvi

Insurance coverage (or non-coverage), claims filed, and disposition of claims.

- Plan for gender analyses in future studies. The collection and analysis of data should differentiate information by gender. Very little about gender similarities and differences has yet been documented.

\section{Program Planning}

When targeting specific audiences, the following should be considered:

- Deliver information by age-appropriate persons. The star or narrator should be close in age to the targeted audience or of a respectful older age.

- Show persons in day-to-day situations that are familiar to the target audience.

- Educate women about their risk of involvement in serious crashes.

- Develop messages that address the particular needs of women drivers, e.g., less stressful driving with children.

- Avoid perpetuating negative stereotypes of women as poor drivers. 


\section{Background}

The 1990's have had the nation's vehicle-related fatality rates at their lowest historical levels. Both men and women seem to be deriving some benefits from current traffic safety programs of public information and education (PI\&E), because crashes are not increasing as fast as travel.

Most highway safety programs of PI\&E over the years have not intentionally targeted by gender, except for high-risk males ages 18 to 25 . However, the National Highway Traffic Safety Administration (NHTSA) wants to explore how it might reach women drivers more effectively with traffic safety messages.

A first step is to determine whether men and women respond differently to traffic safety messages, and how particular differences (and similarities) might be used in the development of future PI\&E programs. One hypothesis for this study was that if men and women had quite different responses to traffic safety messages, then themes and appeals used to convey such messages would need to be redesigned to reach the female population. If reactions were similar, then no such programmatic changes would be necessary, although other interventions would be needed to reduce the number of women dying in car crashes.

\section{A. Review of Current Knowledge About Gender Targeting}

To learn whether or not men and women respond differently to traffic safety messages, S.W. Morris \& Co. conducted a thorough, but surprisingly unproductive, background review, including published and unpublished literature, expert interviews, and meetings with representatives from domestic automobile manufacturers. An exhaustive review of on-line databases, including DIALOG, ProQuest, and UnCover, indicated very little had been published on gender-based research in traffic safety. Further searches revealed very little research had been done on gender-based response differences to any kind of communications program, from commercial advertising to public health and academia. Although there was some information available on how to target each sex, no comparison had been done on whether that technique would work with the opposite sex.

The National Safety Council (NSC), the University of Michigan Transportation Research Institute (UMTRI), and the Roper Center reported no information on gender targeting was available. 
Experts in the fields of health communications and traffic safety reported that unpublished research or current projects had not been conducted on gender targeting, although the research would be of enormous interest.

When these avenues of inquiry had been exhausted, S.W. Morris \& Co. arranged several meetings with representatives from the automobile manufacturing industry, which conducts extensive and ongoing market analyses as it attempts to sell American cars.

The following background review highlights materials from programs and evaluation in traffic safety communications, commercial advertising and marketing, public health communications, and academia.

A complete bibliography, as well as a list of experts and consultants used for this project, are included as Appendix A and Appendix B. Tables A, B, and C in Appendix $\mathbf{C}$ highlight the research and programs that were analyzed.

\section{Traffic Safety Communications}

A review of published literature and interviews with experts indicated no study has examined gender-based response differences to traffic safety communications that deliver messages on such topics as sober driving or the use of child-safety seats and other occupant restraints. For the most part, little program evaluation is ever done for traffic safety communications programs. This shortcoming means information about the efficacy and applicability of the programs cannot be generalized to subgroups of the population.

\section{Commercial Advertising and Marketing}

In the late 1970's and early 1980's, advertisers felt an effective way to market to women would be to depict them as successful, independent career women. ${ }^{1}$ Eventually this strategy backfired: women began to perceive such ads as promoting other stereotypes, such as the woman who has it all or the career woman with nothing else in her life.

Today, marketers of such products as cars, insurance, and housing try to reach both men and women through a variety of media including billboards and "transit cards" on subways, buses, and commuter trains. Given the right product and setting,

${ }^{1}$ Erickson, J.E. (1988, March 7). It's tough to keep up with changes. Advertising Age Special Report: Marketing to Women. p. S-1. 
such out-of-home advertising has very little waste exposure; almost everyone who sees it is a prospect. The many purchasing decisions made by women, or by women and men jointly, almost dictate that entire classes of advertising appeal to both sexes, or at least do not appeal to one at the cost of alienating the other.

Many advertisers now segment their markets less on the basis of gender and other traditional demographic factors, such as age and income, and more on the basis of "lifestyle" characteristics, such as buying habits and leisure time activities.

a. Automobile advertising and marketing. In the 1980's, domestic automobile manufacturers realized that as women began to represent an increasingly large market segment, companies had to target women more directly. Some began to implement a variety of mass media and direct-marketing programs. Chevrolet, Ford, and Toyota have targeted women with specific advertisements at one time or another.

- Chevrolet launched a direct-mail and print campaign as part of its efforts to attract women buyers. The campaign included a mailing to 2.5 million women. The mailing included a brochure on how to buy a car, a certificate for rebates on various Chevrolets, and a 1-year membership in the GM Travel Club. ${ }^{2}$ Chevrolet spent \$100,000 to define "Ms. American Car Buyer," only to conclude that no single profile captured the diversity of American women. Consequently, its "Heartbeat of America" campaign showed diverse women -- young and old, black and white, slender and heavy-set. ${ }^{3}$ More recently, however, Chevrolet has begun to study its marketing strategies "to determine if women are getting the information they want, and if the approach is appropriate and effective. ${ }^{14}$

- Ford established a 20-member task force to develop ways to target women; tactics included road rallies, sponsorship of conferences on professional and lifestyle issues, dealer training programs, and

${ }^{2}$ Candler, J. (1991, January 21). Woman car buyer--Don't call her a niche anymore. Advertising Age Special Report. pp. S-5-6.

${ }^{3}$ Serafin, R. (1988, May 16). Carmakers step up chase for women. Advertising Age. p. 76.

${ }^{4}$ Candler, J. (1986, September 15). Women and the auto market: Unlocking mystery surrounding consumer category. Advertising Age Special Report. pp. S-1, S-4, S-6. 
a speaker's bureau. The group has also used tie-ins with other organizations, such as a program with Jazzercise in which 400,000 women received a free Jazzercise video for test-driving a Mercury Tracer. ${ }^{5}$

- Toyota tried to target women by sponsoring cable television programs, including one called "Women of the 80s." It also sponsored car shows called "Beautiful You," held in major shopping malls. ${ }^{6}$

By the 1990's, these companies had reached a different conclusion, deciding that women are, ". . . not a niche, [they're] mainstream," according to the director of passenger car advertising for General Motor's Chevrolet division. ${ }^{7}$

Although some past marketing efforts focused on very gender-specific advertisements, representatives from some automobile manufacturers say this is no longer so. Instead, gender-neutral ads that promote a vehicle's special features, such as safety and reliability, have become more popular. These gender-neutral ads have proven so effective that companies increasingly rely on them. The corporate placement of the neutral advertising for women during their specific favorite television and radio shows or in magazines became the key to reaching women--not the substance of the advertising itself.

Different companies use different strategies. Toyota opts for gender equality. A company representative says, "Women are featured in some ads, but we are not singling them out. Our ads show men and women. ${ }^{18}$ American Honda Motor Co. reports, "Advertising to address women . . . showing them in typical situations like driving a carpool .... . we don't do that. We are not producing specific ads for specific media." ${ }^{9}$ BMW's corporate communications manager says, "We are using

${ }^{5}$ Serafin, p. 76.

${ }^{6}$ Curtindale, F. (1988, November). Marketing cars to women. American Demographics. p. 30.

${ }^{7}$ Candler, J. (1991, January 21). Woman car buyer--Don't call her a niche anymore. Advertising Age Special Report. pp. S-5-6.

${ }^{8}$ Ibid.

${ }^{9}$ Ibid. 
[women's magazines] but non-sexual, product-oriented ads. ${ }^{10}$ A Mercedes-Benz spokesperson has said that the company targets its advertisements by subject, not by gender. ${ }^{11}$

b. The audience perspective. A minority of men and women surveyed indicated that they sense that ads are gender specific. J.D. Power and Associates found that 25 percent of adults surveyed felt that automobile magazine ads targeted men more than women; 18 percent of men think that television automobile ads target them, while 27 percent of women think that men are targeted with such ads. ${ }^{12}$

\section{Public Health Communications}

The project's search for gender-targeting information was extended to program evaluations and project reports on other public health communications efforts dealing with cancer prevention and treatment, cardiovascular health promotion, and injury prevention and health promotion.

These programs were chosen for several reasons, primarily:

- Most have been in existence for more than 20 years.

- Subject areas have gender-neutral, as well as gender-specific, overtones.

- Background review indicated that some examination of gender-based response differences had been made.

The analysis of the materials provided by specific programs indicated the following general trends. (As with commercial advertising programs, much of the information pertained only to members of one sex; comparative analyses have not been conducted.)

- Health communications messages must target their audiences, especially if such messages are to reach women. ${ }^{13}$

${ }^{10}$ Ibid.

${ }^{11}$ Serafin, R. (1988, May 16). Carmakers step up chase for women. Advertising Age. p. 76.

${ }^{12}$ Serafin, p. 31.

${ }^{13}$ Personal communication with Freimuth, V.S. (1991, October). 
- Women are more active in seeking health information than are men and are much more responsive to health-related messages. ${ }^{14}$

w Women are more likely than men to gather information on behalf of their families and, in fact, men rely on women to obtain such information. ${ }^{15}$

- Women are far more likely to use health information services, such as tollfree telephone information programs. ${ }^{16}$

- Communications planners are coming to realize that several messages may need to be "bundled" together; for example, linking health habits that often occur simultaneously, such as smoking and drinking or drug use and unprotected sexual intercourse. ${ }^{17}$

- Women rely on several sources for health information: media (print and electronic), doctors, and family and friends. ${ }^{18}$

In a cumulative evaluation of programs sponsored by the National Heart, Lung, and Blood Institute, ${ }^{19}$ certain gender-based response differences were found, including:

- Men generally wanted serious, straightforward, strong, and even frightening messages and gave humor a low rating in terms of promoting information

\section{${ }^{14}$ Ibid. \\ ${ }^{15}$ Ibid. \\ ${ }^{16}$ Ibid.}

${ }^{17}$ Office of Disease Prevention and Health Promotion. (1991). Promoting healthy diets and active lifestyles to lower-SES adults: Market research for public education. Washington, DC: Public Health Service.

18 Johnson, J.D. \& Meischke, H. (1991a). Women's preferences for cancer information from specific communications channels. American Behavioral Scientist, 34. pp. 742-55.

${ }^{19}$ Arkin, E.B. (1987, February). Analysis of high blood pressure target audience and message test reports, 1978-1986. Unpublished report for the National Heart, Lung, and Blood Institute. 
about high blood pressure. This is in contrast to their appreciation of humor in commercial advertising.

- Women stressed the need for themes about high blood pressure that promoted the importance of taking care of themselves first. Nonetheless, women felt a major incentive for treatment compliance stems from women's need to meet family obligations. Unless their own health problems are quite serious, women felt family needs take priority over their own health needs.

\section{Academia}

Academic research into gender-based differences typically focuses on one of three approaches:

- The "gender" of the product or brand, e.g., different deodorants or razor blades for men and women;

- "Gendering" of the promotion, e.g., using women in ads for diapers or dish soap and men in ads for oil or lawnmowers; and

- Consumers' gender-relevant roles, e.g., professional women vs. homemakers vs. construction workers.

Advertising and market researchers provide conflicting answers to questions that stem from each of these approaches. Some suggest that women prefer not to be singled out by ads that overtly target them; some suggest that women prefer a "separate but equal" approach. Some find that a female-only approach may alienate men while one market research study concludes, "gender marketing . . . means knowing when to address women as women, men as men, and people as people, regardless of sex. "20

\section{Summary}

When the background review was initially undertaken, it was assumed that much information on gender--seemingly targeting such an obvious one for research-would be found. The converse was true. Little evaluation has been done on the effects of traffic safety mass media campaigns on men and women. Gender-based differences have not been widely studied in most public health education campaigns and non-proprietary advertising research. Within the commercial sector, advertisers

${ }^{20}$ Bellizzi, J. (1991, June 1). Gender positioning of a traditionally male dominant product. Journal of Advertising Research, 31. p. 72. 
are increasingly marketing to women whose lifestyle characteristics (age, income, race, etc.) make them potential customers. The automotive manufacturers indicated that they use the same or similar messages for men and women, but they reach women by choosing media that have a large female audience. Within the public health communications sector, women, unlike men, are reached successfully with messages appealing to them as caretakers and nurturers. Campaigns have relied on women in their role as health information seekers, often on behalf of others. Lastly, academicians studying questions of gender-based response differences offer no conclusive findings. 


\section{Methodology}

\section{A. Overview}

"Focus groups" are small-group discussions, usually involving 8 to 10 people and lasting up to 2 hours, that enable a trained moderator to elicit feelings and attitudes regarding a specified topic.

In late 1992,8 focus groups were conducted with men and women between the ages of 25 and 59 to determine if they perceived traffic safety messages differently.

At the outset of the one and a half hour-long sessions, participants briefly discussed their driving habits and attitudes. Most of the session time was spent eliciting men's and women's responses to television public service announcements (PSAs) reflecting a number of safety-motivating themes on three topics: drinking and driving, speeding, and non-use of seatbelts.

\section{B. Participant Selection}

\section{The Case for Talking to Men and Women}

The original intent of this project was to study women's perceptions of traffic safety messages. It became apparent that these perceptions should not be studied in isolation, but could better be understood by comparing and contrasting them with men's perceptions of the same messages.

If prior studies had already documented similarities and differences in perceptions between men and women, it would have been appropriate to deal only with women in this project. In-depth inquiry into specific subgroups of women could then have provided further insight for directing messages more efficiently to these audiences.

However, the literature did not document clear gender differences. The decision, therefore, was made to have four groups composed of men and four groups of women in order to assess similarities and differences in their perceptions of specific traffic safety messages. 


\section{Age}

Age, along with gender, is an important variable to be considered when developing effective communications. Traffic safety campaigns are no exception.

In meetings with officials from the three domestic automobile manufacturers, it was noted that buyer age is one of the important factors in the marketing of automobiles. Consumer interest in performance, reliability, and safety varied with age. Also, it was indicated that age is used as a surrogate for income, and income typically determines the make and model of car purchased. (It was made clear that women as a whole bought less expensive cars than men because of the differential in income.)

In assembling groups for this study, we also considered group dynamics. Participants closer in age are more comfortable speaking with each other. If there are a few group members that are younger (or older) than the majority of participants, they may feel uncomfortable and not contribute as much as they would in a group with people of similar ages. In order to narrow the study's age range, participants younger than 25 and older than 59 were not included, since they would make the groups too heterogeneous. This age range was then divided into two groups-- 25 to 39 and 40 to 59 years of age.

The following table illustrates the breakdown of the eight groups by gender and age:

\section{Table \#1. Gender/Age Distribution}

\begin{tabular}{||l|c|c||}
\cline { 2 - 3 } \multicolumn{1}{c|}{} & \multicolumn{2}{c|}{ GENDER } \\
\hline \hline AGE & MEN & WOMEN \\
\hline 25 to 39 & 2 Groups & 2 Groups \\
\hline 40 to 59 & 2 Groups & 2 Groups \\
\hline
\end{tabular}

\section{Other Selection/Screening Criteria}

Within the categories of men and women ages 25 to 39 and 40 to 59, NHTSA asked that S.W. Morris \& Co. recruit participants for each group who would represent a mix of ages within each range, educational attainment, marital status, and 
those with and without dependents living at home. Participants had to be licensed drivers who drive at least the national average number of miles for their sex: at least 10,000 miles per year for men and at least 7,000 for women ${ }^{21}$. The groups were not stratified further because of the lack of crash data analysis about high-risk subgroups, e.g., unmarried females with no dependents.

\section{Recruitment}

Participants were recruited through the distribution of flyers and posters in the following locations: grocery stores, libraries, on cars in shopping-mall and mass transit parking lots, churches, health clubs, small businesses, Montgomery County Community College (located in Montgomery County, Maryland), community bulletin boards and recreation centers, large national associations, employee cafeterias and lounges, Federal office buildings, and offices of trucking and local delivery companies. Small display ads were run in community newspapers.

Callers who responded to these flyers and announcements were asked the questions shown in the Participant Screener (Appendix D1).

\section{Participant Characteristics}

A total of 28 men and 32 women participated in the 8 focus groups; the actual number of participants per group varied between 6 and 9 . When the participant characteristics are tallied for group pairs by sex and age, four well-balanced profiles matching the recruitment goals emerge:

${ }^{21}$ Insurance Institute for Highway Safety. (1992). Crash Problem on A Per Mile Basis. Status Report, 27(11). 
Table \#2.

Participant Demographic Profiles

\begin{tabular}{|c|c|c|c|c|c|}
\hline \multirow{2}{*}{\multicolumn{2}{|c|}{$\begin{array}{c}\text { VARIABLE } \\
\text { Age Range in Groups }\end{array}$}} & \multicolumn{2}{|c|}{ MEN } & \multicolumn{2}{|c|}{ WOMEN } \\
\hline & & 25 to 39 & 40 to 59 & 25 to 39 & 40 to 59 \\
\hline \multicolumn{2}{|c|}{ Participant Number } & 13 & 15 & 16 & 16 \\
\hline \multicolumn{2}{|l|}{ Ages } & $\begin{array}{l}25,26,28,29, \\
32,33,34,36, \\
39 \text { ( } 3 \text { were } \\
\text { unspecified })\end{array}$ & $\begin{array}{l}40,43,44,46, \\
48,51,53,56 \\
\text { (4 were } \\
\text { unspecified) }\end{array}$ & $\begin{array}{l}25,26,27,28, \\
29,31,32,34 \\
\text { ( } 2 \text { were } \\
\text { unspecified) }\end{array}$ & $\begin{array}{l}40,41,42,44, \\
45,47,48,54, \\
58(4 \text { were } \\
\text { unspecified })\end{array}$ \\
\hline \multirow{2}{*}{$\begin{array}{l}\text { Marital } \\
\text { Status }\end{array}$} & Single & 7 & 4 & 9 & 7 \\
\hline & Married & 6 & 11 & 7 & 9 \\
\hline \multicolumn{2}{|c|}{ Have Dependents at Home } & 5 & 8 & 7 & 9 \\
\hline \multicolumn{2}{|c|}{$\begin{array}{l}\text { Education (High School } \\
\text { through College) }\end{array}$} & $\begin{array}{l}\text { HS: } 2 \\
\text { Some } \\
\text { College: } 1 \\
\text { College: } 10\end{array}$ & $\begin{array}{l}\text { HS: } 3 \\
\text { Some } \\
\text { College: } 4 \\
\text { College: } 8\end{array}$ & $\begin{array}{l}\text { HS: } 3 \\
\text { Some } \\
\text { College: } 6 \\
\text { College: } 7\end{array}$ & $\begin{array}{l}\text { HS: } 3 \\
\text { Some } \\
\text { College: } 4 \\
\text { College: } 9\end{array}$ \\
\hline \multicolumn{2}{|c|}{ Licensed Drivers } & All & All & All & All \\
\hline \multicolumn{2}{|l|}{ Mileage } & $\begin{array}{c}\text { All } \\
>10,000 / \mathrm{yr}\end{array}$ & $\begin{array}{c}\text { All } \\
>10,000 / \mathrm{yr}\end{array}$ & $\begin{array}{c}\text { All } \\
>7,000 / \mathrm{yr} .\end{array}$ & $\begin{array}{c}\text { All } \\
>7,000 / \mathrm{yr}\end{array}$ \\
\hline \multicolumn{2}{|c|}{$\begin{array}{l}\text { Advertising or Market } \\
\text { Research Profession }\end{array}$} & None & None & None & None \\
\hline
\end{tabular}

One might expect certain self-perceptions and driving behaviors to be associated with a greater likelihood of crash involvement. Through an "exit questionnaire" completed after the discussion, group participants were asked about driving during rush hour, non-use of seatbelts, risk-taking as a driver, speeding, driving after drinking, and being ticketed for a traffic violation. A sample questionnaire and a table summarizing participants' responses are included (Appendices D4 and D5); in general, there was very little difference between men and women. However, more women said they expressed their annoyance to poor drivers, and a few more men said that they never drove after drinking.

\section{Location}

The interviews conducted with experts and the review of previous research produced no information about variations in women's perceptions of safety information as a function of geographical location. This fact, coupled with the lack of 
differences between women's and men's fatal crashes in rural and other locations, indicated that the study did not need to be conducted in multiple sites. Therefore, given the limited budget for travel on this project, all of the groups were held in the Washington, DC, metropolitan area.

\section{Moderator's Guide}

Focus groups are led by experienced moderators who follow a guide for the discussion. The guide covers a sequence of topics, from more general discussion topics to more specific--and perhaps more sensitive--areas. While it serves as a general outline for focus group discussion, it is not a rigid script.

After a warmup where participants were asked to share their name and briefly discuss their commuting distance to work, they were asked some questions regarding general driving issues and traffic safety, e.g., their feelings about driving, whether they liked it or not, and whether their attitudes about driving had changed at all. Participants were then asked to cite any traffic safety messages they could recall and why those messages were so memorable.

To best ascertain whether men and women perceive traffic safety messages differently, a number of safety messages were to be shown in each group. It was hoped that by asking each group the same questions about the same messages, any gender differences in perception would become apparent. Participants were asked to comment on such things as what about the particular message attracted their attention, what they liked or disliked, and whether or not they thought the ad would work better with men or women.

Once the decision had been made to test actual safety messages in the groups, it was then necessary to determine what safety messages should be tested and in what medium--print or broadcast.

At the end of each group, the participants were asked for advice regarding the production of more effective public service announcements (PSAs). They were asked what themes, appeals, and spokesperson characteristics of actors, such as gender and age, would work best to alter behavior.

A sample moderator's guide is included (Appendix D2). 


\section{E. Test Materials Selection}

\section{Choosing Television}

A number of resources were tapped in the effort to gather samples of the most current materials that could be used for this project. Videocassettes of PSAs in particular were readily available in the archives of both S.W. Morris \& Co. and NHTSA, as well as a number of organizations contacted, including the Ad Council, the National Safety Council, and the National Heart, Lung, and Blood Institute.

Television PSAs offered the largest number and greatest variety of test material possibilities. Efforts to locate sample print materials regarding traffic safety issues met with some success, but posters, print advertisements, brochures, and other collateral materials were not as readily available as videocassettes of television PSAs. Radio PSAs were also relatively limited.

After reviewing all the media materials gathered during the background review, television advertisements were selected as the most efficient vehicle to test perceptual differences in the focus group setting at this time. First, participants are very familiar with the medium. Second, each can take 30 seconds to view. Although radio PSAs also take 30 seconds, they are not as appealing. Television ads, because they are visual, provide more stimulus for discussion--a needed variable in this type of research. Most print materials (even some print ads) contain more information but take longer to read and digest. Since we wanted to test messages on three topics-drinking and driving, speeding, and non-use of seatbelts--television seemed likely to be the most effective and efficient mechanism to prompt thought and discussion.

Although each message was evaluated independently by participants, the natural inclination by those who participate in a focus group would be to make comparisons. It was decided not to use materials from more than one medium (e.g., PSAs from radio and television). This helped to keep the focus on reactions to the themes presented rather than on differences resulting from the characteristics of materials in different media.

\section{Narrowing the Field}

The search for television PSAs to use in the focus groups yielded more than 250 for consideration.

Since only a few PSAs could be used in the study, it was necessary to narrow the field of possibilities. A selection strategy with four components was developed: 
- Distinctiveness and diversity of themes or appeals--Each PSA had to have a distinct theme or appeal as a motivator of desired action (e.g., to promote sober driving, show consequences of arrest for DWI; to promote seatbelt use, show risk of facial disfigurement). This was the primary criterion for selecting PSAs.

- Timeliness--PSAs were to have been produced after 1989, if at all possible.

- Production value--PSAs were to have been executed in such a way that they would be considered of relatively good quality.

- Females as a target audience--A number of the test PSAs were to have had some element that would likely catch the attention of females, such as a female voiceover, a female protagonist, etc.

By placing candidate television PSAs in categories combining three highway safety topics--drinking and driving, speeding, and non-use of seatbelts--and six safetymotivating themes and appeals, the field was immediately narrowed to a small number of finalists. PSAs were eliminated usually because they were either outdated, lacked the necessary production quality, or did not meet the other evaluation criteria.

The candidate PSAs reflected the six designated themes and appeals within the three safety topic categories (see Table \#3, page 17).

The following themes and appeals were used to choose the PSAs to be shown in the focus groups:

- Enforcement risks.

- Physical injury to self or to others as a result of negligence or breaking a traffic law.

- Fatality risks to self or to others.

- Endorsement or normative appeal: implies that "everybody's doing it" or "there's something wrong with you if you don't do it."

- Financial costs: depicts how disobeying a law can result in financial loss through a fine or higher insurance premiums. 
- Personal/moral/social responsibility: emphasizes making a specific intervention to stop unsafe driving because it is the responsible thing to do.

The 27 candidate PSAs considered in the final selection of PSAs for the focus groups are described in Table \#3.

Once the number of choices had been narrowed to a more manageable size, each candidate PSA was carefully reviewed in relation to the assigned criteria. S.W. Morris \& Co. recommended six PSAs that offered the most logical and best possible combinations of the three highway safety topics. NHTSA approved S.W. Morris \& Co.'s recommendations. A seventh PSA on seatbelt non-use and social responsibility was added after two focus groups proved there was time to view and discuss one more PSA (see Table \#4, page 19).

The original six PSAs, all with different appeals, offered an array of additional elements for participants to react to, such as format, use of models, location, audio delivery, target age, and source (see Table \#5, page 20). The PSAs were all of approximately the same production quality. Focus group participants would, therefore, be asked questions that emphasized the content of the message delivered as opposed to its style of delivery and production values. In narrowing the finalists to six choices, many very high-quality and effective messages had to be dropped in order to make sure the final combined set met the established themes and appeals profile.

After each PSA was shown in the group, participants were asked to complete a rating form on their reactions (Appendix D3); group discussion followed. 
Table \#3. Message Themes and Highway Safety Topics of Television PSAs Considered for Use in Focus Groups

\begin{tabular}{|c|c|c|c|}
\hline \multirow[t]{2}{*}{ Theme } & \multicolumn{3}{|c|}{ Unsafe Behavior Topic } \\
\hline & $\begin{array}{c}\text { Drinking and Driving } \\
\text { Choose } 2\end{array}$ & $\begin{array}{c}\text { Seatbelt Non-Use } \\
\text { Choose } 2\end{array}$ & $\begin{array}{l}\text { Speeding } \\
\text { Choose } 2\end{array}$ \\
\hline $\begin{array}{l}\text { Enforcement } \\
\text { Risks } \\
\text { Choose } 1\end{array}$ & $\begin{array}{l}\text { Female drunk driver gets arrested and thrown } \\
\text { in jail; female protagonist. } \\
\text { Game show parody of possible consequences } \\
\text { (low production quality). }\end{array}$ & $\begin{array}{l}\text { "Summertime Blues" (1992); buckle up or } \\
\text { face getting a ticket (quick cuts approach). }\end{array}$ & $\begin{array}{l}\text { Most often heard excuses about speeding; } \\
\text { ends with a cop and his promise to pull you } \\
\text { over. }\end{array}$ \\
\hline $\begin{array}{l}\text { Physical } \\
\text { Injury to Self } \\
\text { or } \\
\text { to Others } \\
\text { Choose } 1\end{array}$ & $\begin{array}{l}\text { Males in crash; illustrates grisly repercussions } \\
\text { of drinking and driving. } \\
\text { "Kevin" (1991-92); illustrates what can happen } \\
\text { if you choose not to take the keys and look } \\
\text { out for your own safety. }\end{array}$ & $\begin{array}{l}\text { Female as protagonist; threat of facial } \\
\text { disfigurement (older PSA). } \\
\text { Comparative consequences with seatbelt } \\
\text { holding car above a driver. }\end{array}$ & $\begin{array}{l}\text { "Sara"; woman who is in a wheelchair as a } \\
\text { result of speeding; woman is never shown; } \\
\text { female voiceover. }\end{array}$ \\
\hline $\begin{array}{l}\text { Fatality } \\
\text { Risks to } \\
\text { Self or } \\
\text { to Others } \\
\text { Choose } 1\end{array}$ & $\begin{array}{l}\text { "Jennifer"; male in hospital living with the } \\
\text { guilt of having killed his new wife when } \\
\text { drinking and driving (older PSA). } \\
\text { Male drunk driver speaking from the grave } \\
\text { about how he shouldn't have. }\end{array}$ & $\begin{array}{l}\text { Barbara Mandrell's testimonial about how } \\
\text { seatbelts saved the lives of herself and her } \\
\text { family (older PSA). }\end{array}$ & $\begin{array}{l}\text { "Unanswered Questions"; woman driver runs } \\
\text { down an older couple and older woman is } \\
\text { hurt; conveys no reason is good enough to } \\
\text { speed (newer PSA). } \\
\text { Woman speaking to the camera about the } \\
\text { responsibility people have to not speed } \\
\text { through residential areas (older PSA). }\end{array}$ \\
\hline
\end{tabular}


Table \#3. Message Themes and Highway Safety Topics of Television PSAs
Considered for Use in Focus Groups (Continued)

\begin{tabular}{|c|c|c|c|}
\hline \multirow[t]{2}{*}{ Theme } & \multicolumn{3}{|c|}{ Unsafe Behavior Topic } \\
\hline & $\begin{array}{l}\text { Drinking and Driving } \\
\text { Choose } 2\end{array}$ & $\begin{array}{l}\text { Seatbelt Non-Use } \\
\text { Choose } 2\end{array}$ & $\begin{array}{l}\text { Speeding } \\
\text { Choose } 2\end{array}$ \\
\hline $\begin{array}{c}\text { Endorsement } \\
\text { or Normative } \\
\text { Appeal } \\
\text { Choose } 1\end{array}$ & $\begin{array}{l}\text { "Crashing Glasses" (1992); Friends Don't Let } \\
\text { Friends Drive Drunk. }\end{array}$ & $\begin{array}{l}\text { Oak Ridge Boys tell you to buckle up. } \\
\text { Vince and Larry, everyone's listening and } \\
\text { buckling up. } \\
\text { Vince and Larry, only dummies don't buckle } \\
\text { up. }\end{array}$ & N/A \\
\hline $\begin{array}{l}\text { Financial } \\
\text { Costs } \\
\text { Choose } 1 \\
\end{array}$ & $\begin{array}{l}\text { Itemized approach to the financial costs of } \\
\text { drinking and driving. }\end{array}$ & $\begin{array}{l}\text { Couple pulled over by a cop for not wearing } \\
\text { seatbelts and is fined; male voiceover. }\end{array}$ & $\begin{array}{l}\text { Gender-neutral PSA about dashboard } \\
\text { indicator of fines and increased insurance } \\
\text { premiums as a result of speeding. }\end{array}$ \\
\hline $\begin{array}{c}\text { Personal/ } \\
\text { Moral/Social } \\
\text { Responsibility }\end{array}$ & $\begin{array}{l}\text { Woman who feels she would have lost a friend } \\
\text { had she not intervened to take the car keys of } \\
\text { a woman friend who had drunk too much } \\
\text { (older PSA). } \\
\text { Ad Council PSA; "Mike" (1991); female } \\
\text { voiceover; lost a boyfriend because she didn't } \\
\text { stop him from drinking and driving. }\end{array}$ & $\begin{array}{l}\text { Two men converse about buckling up, } \\
\text { addresses the element of friendship and caring } \\
\text { between males. } \\
\text { Children speaking to the camera saying } \\
\text { parents love their kids and that's why they } \\
\text { make them wear seatbelts. } \\
\text { Comparison that seatbelts are like hugging } \\
\text { your child. }\end{array}$ & $\begin{array}{l}\text { Plea not to speed in school zones; shows kids } \\
\text { going to school (looks like an older PSA). }\end{array}$ \\
\hline
\end{tabular}


Table \#4. Recommended PSAs for Gender Focus Groups

\begin{tabular}{|c|c|c|c|c|c|}
\hline Enforcement Risks & $\begin{array}{l}\text { Physical Injury to } \\
\text { Self or to Others }\end{array}$ & $\begin{array}{l}\text { Fatality Risks to Self } \\
\text { or to Others }\end{array}$ & $\begin{array}{l}\text { Endorsement or } \\
\text { Normative Appeal }\end{array}$ & Financial Costs & $\begin{array}{l}\text { Personal/ } \\
\text { Moral/Social } \\
\text { Responsibility }\end{array}$ \\
\hline $\begin{array}{l}\text { Chosen PSA 1 } \\
\text { Topic: Drinking and } \\
\text { Driving } \\
\text { S.C. Department of } \\
\text { Highways PSA. } \\
\text { Young woman } \\
\text { arrested for drinking } \\
\text { and driving, } \\
\text { documentary } \\
\text { approach. }\end{array}$ & $\begin{array}{l}\text { Chosen PSA } 2 \\
\text { Topic: Seatbelt Non- } \\
\text { Use } \\
\text { Missouri State } \\
\text { Highway Patrol. } \\
\text { Appeal to women to } \\
\text { wear seatbelts to } \\
\text { avoid facial } \\
\text { disfigurement. }\end{array}$ & $\begin{array}{l}\text { Chosen PSA } 3 \\
\text { Topic: Speeding } \\
\text { NHTSA/DOT PSA, } \\
\text { "Unanswered } \\
\text { Questions." Female } \\
\text { driver in a hurry and } \\
\text { hits elderly couple. }\end{array}$ & $\begin{array}{l}\text { Chosen PSA } 4 \\
\text { Topic: Seatbelt Non- } \\
\text { Use } \\
\text { DOT PSA, "Vince } \\
\text { and Larry." Don't } \\
\text { be a dummy, only } \\
\text { dummies don't buckle } \\
\text { their seatbelts. }\end{array}$ & $\begin{array}{l}\text { Chosen PSA 5 } \\
\text { Topic: Speeding } \\
\text { Florida Highway } \\
\text { Patrol. Gender- } \\
\text { neutral PSA. } \\
\text { Discusses fines and } \\
\text { increased insurance } \\
\text { rates using visuals. }\end{array}$ & $\begin{array}{l}\text { Chosen PSA } 6 \\
\text { Topic: Drinking } \\
\text { and Driving } \\
\text { Ad Council PSA, } \\
\text { "Mike." Female } \\
\text { voiceover, saying } \\
\text { how she could have } \\
\text { saved Mike's life } \\
\text { had she taken his } \\
\text { keys. }\end{array}$ \\
\hline $\begin{array}{l}\text { Alternate PSA } 1 \\
\text { Topic: Seatbelt } \\
\text { Non-Use } \\
\text { "Summertime } \\
\text { Blues," 1992, DOT. } \\
\text { Quick cuts visual } \\
\text { appeal approach. }\end{array}$ & $\begin{array}{l}\text { Alternate PSA } 2 \\
\text { Topic: Speeding } \\
\text { NHTSA/DOT PSA, } \\
\text { "Sara." Woman in a } \\
\text { wheelchair as a result } \\
\text { of speeding accident. }\end{array}$ & $\begin{array}{l}\text { Alternate PSA } 3 \\
\text { Topic: Seatbelt Non- } \\
\text { Use } \\
\text { American Academy } \\
\text { of Orthopedic } \\
\text { Surgeons/NHTSA } \\
\text { PSA. Testimonial by } \\
\text { Barbara Mandrell } \\
\text { after her accident that } \\
\text { seatbelts saved her } \\
\text { and her family's } \\
\text { lives. }\end{array}$ & $\begin{array}{l}\text { Alternate PSA } 4 \\
\text { Topic: Drinking and } \\
\text { Driving } \\
\text { Ad Council PSA, } \\
\text { "Crashing Glasses." } \\
\text { Friends Don't Let } \\
\text { Friends Drive Drunk. }\end{array}$ & $\begin{array}{l}\text { Alternate PSA } 5 \\
\text { Topic: Seatbelt Non- } \\
\text { Use } \\
\text { Washington State } \\
\text { Highway Patrol. } \\
\text { Couple is pulled over } \\
\text { and fined for not } \\
\text { wearing seatbelts. } \\
\text { Game show, "have } \\
\text { we got a deal for } \\
\text { you" approach. }\end{array}$ & $\begin{array}{l}\text { Chosen PSA } 7 \\
\text { Topic: Seatbelt } \\
\text { Non-Use } \\
\text { Project Lifesaver } \\
\text { PSA with two men. } \\
\text { Overheard } \\
\text { conversation } \\
\text { approach about } \\
\text { seatbelt use. } \\
\text { This PSA was } \\
\text { added to the above } \\
\text { six after the first } \\
\text { night of focus } \\
\text { groups proved there } \\
\text { was time for an } \\
\text { additional one. }\end{array}$ \\
\hline
\end{tabular}


Table \#5. Characteristics of Chosen PSAs by Theme

\begin{tabular}{|c|c|c|c|c|c|c|c|}
\hline & $\begin{array}{c}\text { PSA } \\
\# 1\end{array}$ & $\begin{array}{c}\text { PSA } \\
\# 2 \\
\end{array}$ & $\begin{array}{c}\text { PSA } \\
\# 3\end{array}$ & $\begin{array}{c}\text { PSA } \\
\# 4 \\
\end{array}$ & $\begin{array}{c}\text { PSA } \\
\# 5\end{array}$ & $\begin{array}{c}\text { PSA } \\
\# 6\end{array}$ & $\begin{array}{c}\text { PSA } \\
\# 7\end{array}$ \\
\hline Theme & Enforcement Risks & $\begin{array}{l}\text { Physical Injury to } \\
\text { Self or to Others }\end{array}$ & $\begin{array}{l}\text { Fatality Risks to Self or } \\
\text { to Others }\end{array}$ & $\begin{array}{l}\text { Endorsement or } \\
\text { Normative Appeal }\end{array}$ & Financial Costs & $\begin{array}{l}\text { Personal } \\
\text { Responsibility/Guilt/Love }\end{array}$ & $\begin{array}{l}\text { Personal } \\
\text { Responsibility/Friendship }\end{array}$ \\
\hline Topic & Drinking and Driving & Seatbelt Non-Use & Speeding & Seatbelt Non-Use & Speeding & Drinking and Driving & Seatbelt Non-Use \\
\hline Title & $\begin{array}{l}\text { The Next } 60 \text { min. of Yo } \\
\text { ur Life }\end{array}$ & $\begin{array}{l}\text { The First Law of } \\
\text { Motion }\end{array}$ & Answer the Question & Vince and Larry & $\begin{array}{l}\text { Speeding Can Wreck } \\
\text { Your Day }\end{array}$ & Mike & $\begin{array}{l}\text { Project Lifesaver: Snap It } \\
\text { Up }\end{array}$ \\
\hline $\begin{array}{l}\text { Format } \\
(30 \text { sec.) }\end{array}$ & Dramatic portrayal & Symbolism & Dramatization & Demonstration & $\begin{array}{l}\text { Use of visuals to } \\
\text { support audio } \\
\text { message }\end{array}$ & $\begin{array}{l}\text { Testimonial, audio only, } \\
\text { and dramatic portrayal }\end{array}$ & $\begin{array}{l}\text { Dramatization, overheard } \\
\text { conversation }\end{array}$ \\
\hline \multicolumn{8}{|l|}{ Use of Actors } \\
\hline Age & Younger, 20s & $20 \mathrm{~s}$ to $30 \mathrm{~s}$ & $\begin{array}{l}30 \text { s to } 40 \text { s driver, } \\
\text { elderly victim }\end{array}$ & N/A & N/A & N/A & $30 \mathrm{~s}$ \\
\hline Sex & Female & Female & Females & Males & N/A & N/A & Male protagonists \\
\hline Attractiveness & All-American & $\begin{array}{l}\text { Pretty young } \\
\text { woman }\end{array}$ & N/A & N/A & N/A & N/A & Athletic types \\
\hline Race & White & White & White & N/A & N/A & N/A & White \\
\hline $\begin{array}{r}\text { Socioeconomic } \\
\text { Status }\end{array}$ & Middle class & Unknown, N/A & $\begin{array}{l}\text { Middle class } \\
\text { neighborhood/street }\end{array}$ & Unknown & N/A & $\mathrm{N} / \mathrm{A}$ & Middle class \\
\hline Graphics & Black and White & $\begin{array}{l}\text { Color, shattering of } \\
\text { screen/image effect }\end{array}$ & N/A & $\begin{array}{l}\text { Cartoon-like } \\
\text { dramatization }\end{array}$ & $\begin{array}{l}\text { Color, dashboard } \\
\text { electronics motif }\end{array}$ & Color visuals & N/A \\
\hline Location & $\begin{array}{l}\text { Outdoors, highway } \\
\text { setting }\end{array}$ & Unspecified & $\begin{array}{l}\text { Middle class } \\
\text { neighborhood/street }\end{array}$ & Indoors, safety lab & $\mathrm{N} / \mathrm{A}$ & Outdoors, gravesite & $\begin{array}{l}\text { Parking lot after a tennis } \\
\text { match, in car }\end{array}$ \\
\hline $\begin{array}{l}\text { Audio } \\
\text { Delivery }\end{array}$ & Voiceover, male & Voiceover, male & $\begin{array}{l}\text { Overheard voiceover } \\
\text { and direct delivery to } \\
\text { camera }\end{array}$ & $\begin{array}{l}\text { Direct from } \\
\text { characters, voiceover } \\
\text { male on tagline }\end{array}$ & Voiceover, male & $\begin{array}{l}\text { Voiceover, female } \\
\text { protagonist }\end{array}$ & Male conversation \\
\hline Source & $\begin{array}{l}\text { S.C. Dept. of Highways } \\
\text { and Public } \\
\text { Transportation }\end{array}$ & $\begin{array}{l}\text { Missouri State } \\
\text { Highway Patrol }\end{array}$ & DOT & DOT/Ad Council & $\begin{array}{l}\text { Florida Highway } \\
\text { Patrol }\end{array}$ & Ad Council/NHTSA/DOT & Project Lifesaver \\
\hline Tagline & $\begin{array}{l}\text { Highways or Dieways, } \\
\text { The Choice is Yours. }\end{array}$ & $\begin{array}{l}\text { Buckle Up. The } \\
\text { First Law of } \\
\text { Motion. }\end{array}$ & $\begin{array}{l}\text { Speeding Gets You } \\
\text { Nowhere. Fast. }\end{array}$ & $\begin{array}{l}\text { You Could Learn A } \\
\text { Lot From A Dummy. } \\
\text { Buckle Your Safety } \\
\text { Belt. }\end{array}$ & $\begin{array}{l}\text { Speeding Can Wreck } \\
\text { Your Day. }\end{array}$ & $\begin{array}{l}\text { Friends Don't Let Friends } \\
\text { Drive Drunk. }\end{array}$ & Snap It Up. \\
\hline
\end{tabular}




\section{Findings}

This chapter highlights focus group discussions of the PSA themes and summarizes session comments about driving attitudes and habits, communication styles and behaviors, and tailoring safety messages for men and women.

Generalizations from the focus groups should be regarded as highly tentative, since reactions were shaped to some extent by the interaction among the safety topics, the themes/appeals, and production techniques. Since the study employed only a few PSAs, simultaneous variations among these elements were unavoidable. Only the use of a large number of PSAs, holding some factors constant while varying others in a systematic way, would permit unambiguous attribution of effects to certain themes rather than other factors.

The discussions of participants are summarized in the following order:

Driving attitudes and habits

Reactions to the PSAs

Participant suggestions for appealing to men and women

Communications style and behaviors.

\section{A. Driving Attitudes and Habits}

Drivers described a range of attitudes about the act of driving. Attitudes ranged from a sense of frustration at external problems, such as highway construction, discourteous drivers, and increased traffic congestion, to a sense of pleasure at the solitude of driving alone. Younger women were least likely to consider driving a pleasure; many reported that they have rearranged their work schedules to avoid rushhour hassles. Others stated that driving is simply a means to an end, one they would avoid if they could. The following quotes represent views heard in the groups: 
"I enjoy driving for recreation. " [YM] *

"Driving recreational with my family--it's wonderful." [YM]

"Traffic is getting worse and worse here. I say a prayer before I get in the car. " [YM]

"My life is mostly carpooling my three children. I feel like I live in my car." [OW]

"I like to drive alone, not with my husband. When I'm alone I can think. I'm 45 and I still like to play the radio. " [OW]

"I use driving as a time for myself. I use the car phone and feel secure. I feel at peace." [OW]

"The older I get, the less I enjoy driving. Not so much the driving itself [but the time it takes.]" [OM]

Many participants described how their attitudes toward driving have changed over the years. Several attributed these changes to the attitudes and behaviors of other drivers.

"I see guys in fancy cars trying to take advantage of any break in traffic.

I try to stay away from recklessness. " [YM]

"I used to take any chance I had to drive, but not anymore. People are really rude and inconsiderate. "[YW]

"People behind the wheel are becoming shorter and shorter with other drivers. " [OM]

* $\quad \mathrm{YM}=$ Younger Man (age 25 to 39)

$\mathrm{YW}=$ Younger Woman (age 25 to 39 )

$\mathrm{OM}=$ Older Man (age 40 to 59 )

OW $=$ Older Woman (age 40 to 59 ) 
"I try to use common courtesy, let people in my lane, but more and more, even when you do let them in, they don't even give you a thankyou wave." [YW]

Many participants said their attitudes toward driving have changed as a result of growing older and becoming more mature, having children, or discovering that the aging process has diminished some of their skills.

"When you get your license when you're 16, you want to drive everywhere, go to the store for your mother and cruise around. It's not like you do that anymore. " [YM]

"Now as I get older, I notice an increase in accidents, so I view it as a potentially lethal activity. When you're younger, you feel more immortal. Now, when I see a group of big trucks, I want to stay away from it. " [YM]

"I don't like driving at night. Wearing bifocals makes it hard [to see at night]. I am more tentative, less comfortable. " [OW]

"Life has gotten more complicated as I've gotten older... When you're young, you take off and you're free. Now, [driving] is in the way of me getting from one place to another. " [OW]

"Since I've had my child, I'm more considerate. I wouldn't take a chance that was iffy, whereas I might have before. " [YW]

Younger women were more apt to describe themselves as being very aggressive and assertive when behind the wheel. One might have expected such comments from younger men, but they were actually more likely to describe themselves as having become more defensive and more cautious when driving. This trend among younger women drivers supports some of the traffic statistics described in the background review. (It may be that women are more likely to report driving aggressively; men may be less likely to admit to aggressive driving.)

"I probably drive too fast. If I get behind someone doing 35 when the speed limit is 50, I get really upset and pass them as soon as there's an opening. I ride a motorcycle too. I know what I'm doing. I never cause an accident." [YW] 
"I'm a fine-honed driver. I hit those brakes faster than anybody else." [YW]

"I'm an aggressive driver...I'm not unsafe, I'm aggressive. I drive fast...I know my car and how much space I need to maneuver it. " [YW]

"I'm very aggressive behind the wheel. I feel like I need to be where I was going five minutes ago." [YW]

"I've become more impatient and unhappy behind the wheel. I can't stand sitting in a line of brakes for twenty minutes and not moving." [YW]

Some groups were asked to describe how stress affects their driving ability. Temperament, not gender, seemed to be the critical factor in these responses, with some men and women reporting they don't let things get to them, and others reporting a stressful day at work translates into a frustrated time at the wheel. One group of young men all agreed that stress causes them to be more aggressive when they drive. Older men reported they are better able to compartmentalize their lives and leave the day's stresses at work. One man simply tells himself to "cool it on the highway."

"I'm a little more spiteful if I've had a bad day. " [YW]

"If I've had a bad day or I'm in a bad mood, I'm careless. I don't pay attention--that's my way of unwinding. " [YW]

"You go to work and things start off [being bad] and I get in the van to do my route, I have a tendency to speed and take chances I don't normally take....It just upsets you and you take it out on the road. " [OM]

"I'm sure I do [take it out on the road], but I can't think offhand what it is. " [OM]

"Things upset me but I don't let it affect my driving. I care about my life. "[OM]

"People in general, when they get behind the wheel, are still having the kids, the wife, the job, and driving is not taken as seriously as what driving should be taken today. The bottom line is when you buckle up, your focal point is what is behind you and what is in front of you. And 
not what you brought into the car when you sat down. And basically... they are not paying attention... because of the stress level. " [OM]

Only women mentioned the stress of driving with children in the car.

"I have three kids in the car and when they start [acting up] I lose my mind. I will not go if I have to sit in traffic with the kids. " [YW]

"If the kids are in the car I lose my patience. I can't hear, think, or see I get so stressed out. I have to stop the car. It's very stressful having kids in the car, then having some idiot pull out in front of you. " [YW]

All drivers described a range of traffic violations they have seen other drivers make, especially speeding, passing on the wrong side of the road or on the right, running red lights or stop signs, and not using turn signals. Many older drivers also noted the problem of drivers who do not slow down for yellow traffic signals, and who use their horns illegally, out of anger and not for an emergency. Younger women drivers also reported other drivers who do not put their children in child-safety seats.

When asked to describe their own offenses, people were more limited in their responses, primarily citing speeding and failure to always wear seatbelts as their primary offenses.

\section{B. Recollections of Televised PSAs}

Participants were then asked to recall traffic safety PSAs they had seen on television. Younger women seemed to have an easier time listing a range of PSAs. In many groups, very few people were able to describe any PSAs, although many participants described highway traffic signs with messages about wearing seatbelts or not speeding. The PSAs most often mentioned were those featuring Vince and Larry, as well as PSAs concerned with drinking and driving, such as the "Friends Don't Let Friends Drive Drunk" and designated driver campaigns.

Several participants described the GEICO Insurance Company seatbelt ad in which a child on a parent's lap turns into a Sumo wrestler on impact. In one group, younger men discussed the appeal of this particular ad, remarking that they like the ad because it relates to them in their roles as parents and uses humor to communicate effectively. 
Asked why they recalled certain PSAs, male participants pointed to the humorous approach taken by NHTSA's "Vince and Larry" campaigns. Women recalled PSAs they characterized as being tragic or that featured the consequences of certain actions. One older woman said she recalls drinking and driving PSAs because of the continuity of anti-drinking and driving campaigns.

\section{Reactions to PSAs Shown in Focus Groups}

After this general discussion, participants were shown seven PSAs. The paragraphs that follow summarize the discussion that took place after viewing each of the PSAs.

Direct quotations from participants are included to illustrate the report's findings and support its conclusions. A brief description of each PSA is also included in this section.

\section{PSA \#1}

\section{Theme: Enforcement Risks}

Topic: Drinking and Driving

Title: "The Next 60 Minutes of Your Life"

This PSA targets young people and uses an enforcement theme as a deterrent to drinking and driving. A male narrator introduces the PSA using a tag line "This could be the next 60 minutes of your life!" A teenage girl, seemingly dressed for a prom, is shown drinking and driving. A policeman pulls her over. We see the girl trying to walk a straight line. The girl is taken to jail, and we watch as her mug shot is taken and she is led to a cell. The action is very fragmentary, with each scene lasting only a few seconds. The PSA is produced in black-and-white.

For the most part, drivers of both sexes and in all age groups said the PSA's message was lost in the unclear narrative theme line and in the jumble of images. Most participants said the PSA conveyed an important message, but felt it provided no new information. Even younger drivers, who might be more accustomed to watching music videos and MTV (Music Television), found the sequencing and fast pace difficult to follow. A few participants, however, said it was precisely the choppiness of the PSA that most caught and held their attention. 
In reacting to this PSA and to others, group participants answered a question about what they regarded as the "main message" by describing the desired action (avoid driving while intoxicated, wear seatbelts, etc.) rather than the theme or motivational appeal (avoid bad experience of arrest, avoid injury, etc.) They obviously understood both the intention and the basis for it, but they focused on the recommended action rather than the reason for taking it.

Many men in the groups responded to the quality of the production itself-whether or not the PSA should have been in color or black-and-white, the camera angles, the clarity of the voices--while many women responded to its content. One man, for example, said, "Give me good dialogue and good pictures." Women, especially those with adolescent children, responded more often to the PSA's content.

"That ad relates [to me] because I have a 15-year-old and a 13-year-old --they're starting to date and getting into situations with alcohol. I would want my kids to see that ad. I want a lot of those kinds of ads on." [OW]

Several participants found the PSA too jumpy for their tastes.

"I would have missed the message. It was too fast. " [YM]

"It was too jumbled." [OM]

"Unclear, not visually powerful, just visually hectic. " [YM]

"It went sort of fast and I normally tend to not watch commercials. So I would probably have missed the message. " [OM]

Others disagreed, saying that the PSA offered a slice of reality, a sense of how it might feel to be arrested for drinking and driving.

"I liked it. Isn't that the way it usually happens? That's as quickly as it can happen. " [YW]

"Everything is so quick, and your response, and when you're drunk....The way it was portrayed is as quickly as it can happen if you're in an accident. " [YM]

"It gave me the chills. You know exactly what they were trying to say." [YW] 
"I'd like to watch it because I want my kids to know that this is what the fast-paced world is really like." [OM]

The men in the groups, more than women, seemed to have trouble identifying with the young girl in the PSA. One man expressed his surprise at seeing a woman shown in this situation. Another said, "I didn't identify with the woman. But if I was going out, I wouldn't want to put a woman in that position."

All drivers believed the PSA's exclusive focus on a younger audience, primarily through the use of a young female in a prom dress, rendered the PSA ineffectual for older viewers. To reach older viewers, participants suggested using older actors who are involved in adult-like situations, such as business lunches or after-work happy hours. One man recommended appealing to male viewers through celebrity athletes who have been involved in drinking and driving crashes. One woman recommended showing women at a "respectable dinner" drinking socially and then driving and being arrested. Participants ages 25 to 59 wanted PSAs that were relevant to and reflective of their own lives.

"It was geared toward teenagers, not me. I didn't feel like it appealed to me because I am an occasional drinker. I've never driven when I was drinking. It still hit home, but not as much as something with adults or more serious injury." [YW]

"Show women at dinner at someone's house--have dinner and a glass of wine. I would go to a friend's house and have a few drinks, and I'm a small person and if I got pulled over, I would get arrested." [YW]

"Show something realistic to a 30-year-old." [YW]

A number of men and women did point out that a PSA like this did hit home with them because they are parents. They felt the PSA was important for younger viewers to see because it illustrates the shame and embarrassment that one suffers when being arrested.

"I have a daughter and this definitely has an impact on me." [OM]

"The young people are the ones having the accidents out there. It's important that they see this." [OM]

"I like that ad because it relates to my kids. It scares me, but I want my kids to see it." [OW] 
jail." [YW]

"It definitely shows you the humiliation of being handcuffed and then going to

\section{PSA \#2}

Theme: Physical Injury to Self or to Others

Topic: Seatbelt Non-Use

Title: "The First Law of Motion"

This second PSA again targets a younger audience, using an attractive young woman to deliver a message about the importance of seatbelt use. The theme is fear of disfigurement. The narrator asks the viewer to watch what happens to a pretty face when it is "speeded up" to 50 miles an hour. The face becomes distorted, widening in an exaggerated way to appear deformed. As the sound of a crash is heard, with shattering glass, the picture of the girl's face breaks and falls in pieces; a disfiguring injury is clearly implied but not shown. The narrator says, "Without a seatbelt, the results can be pretty ugly."

Responses to this PSA were varied. It clearly appealed to some viewers and not to others. Once again, viewers saw the message but said they learned nothing new.

For example, many men in the groups said the actress was not pretty enough, while many females thought she was so pretty, her face would appeal to all ages and both sexes.

"The girl wasn't attractive. You didn't really see the results of what would have happened to her. " [YM]

Once again, many men tended to focus on the production values; one complained that it was a low-budget production. A few women in the groups also had problems with the production itself, saying it was "as hokey as a home video." Both the men and women in the groups found the special effect of extending the actress' face a bit absurd, commenting that one's face doesn't distort at high speeds.

"Too elementary and slow for me." [YM]

"The overall presentation was kind of predictable and bland. " [YM] 
One man found the message of the ad a bit diffuse.

"I thought it was a hair commercial." [OM]

In contrast to the first PSA, however, men found this PSA more direct and straightforward. Its brevity also appealed to them.

"I could absorb what they were saying a little more." [OM]

Younger female participants were sensitive to the PSA's theme to play upon their vanity by appealing to concerns about appearance. Several found this approach offensive and inappropriate. After all, many reasoned, more than a face is destroyed when a person goes through a windshield. Older women, on the other hand, were struck by the attractiveness of the model.

"It was pretty hokey. I'd think more of my life than my face...I'd worry about my life more." [YW]

"You're destroying somebody's life, not just somebody's pretty face. The point to get across is the importance of wearing a seatbelt. There are more important things than looks. "[YW]

"It doesn't have to be a pretty face." [YW]

One younger female participant dissented, saying, "But people (women) are so consumed with image, the use of the face was effective." One older women liked the use of appealing looks, saying, "It's hard to picture her not pretty. Seeing something pretty appeals to something...."

There was no consensus within and among groups about whether or not the PSA should have portrayed more graphically the effects of an accident.

"It should have been more graphic to show what can happen if you go through a windshield." [YM]

"I was hoping it wouldn't be gruesome. I was a little tense. But that tenseness was effective." [YW]

To make the PSA more effective, participants suggested making it more graphic, showing the physical consequences of an accident without showing a great 
deal of gore. For example, some participants recommended showing the actress's scarred face before and after undergoing multiple unsuccessful plastic surgeries.

"Let's face it, gruesome works. Showing me a scarred face afterward would have made an impact." [YW]

"There were no results shown. It would have made a greater impression on me if it was more graphic." [YM]

"I don't want to see blood, but somehow they need to convey the repercussions like a woman after plastic surgery." [OW]

A group of younger female participants suggested using children in the PSA and appealing to people's emotional responses toward children.

"You don't want to see anything bad happen to a child. That's really gruesome. The child doesn't have a choice. " [YM]

\section{PSA \#3}

Theme: $\quad$ Fatality Risks to Self or to Others

Topic: $\quad$ Speeding

Title: $\quad$ "Answer the Question"

A driver is shown looking at her watch and a female voice says, "Oh no," as she contemplates a line of residential traffic in front of her. She whips out around the cars, speeds left into a residential side street. We see an older man and woman with shocked expressions on their faces before the car hits them. The next shot shows a person on a stretcher, while close-ups of a policeman and several outraged neighbors ask demanding questions, such as "What did you think you were doing?" At the end, the narrator asks, "So why can't you answer their questions?"

Many participants responded favorably to this approach. The information provided and the range of actors featured, from children to the elderly, appealed to men and women. As one young woman noted, the PSA "covered everything. It was tense. It covered all ages. Very realistic in this area." 
Most participants identified with some aspect of the PSA and in doing so found they had learned something about driving safely. Many said the message reminded them of the importance of obeying the speed limits in residential neighborhoods.

"I could identify with being stuck in traffic. " [YM]

"I can identify--if I think I'm going to miss the train, there's a real temptation to speed." [YM]

"You could easily put yourself in that situation. " [YM]

"It definitely caught my eye; that can happen." [YW]

"It was good but it gave you the creeps. " [OW]

"What more horrible thing [could happen] than to hit a person who is walking?" [OW]

Some participants felt that in addition to the messages about not speeding, the PSA offered important information on being "a better pedestrian." The men questioned aspects of the production itself. Some complained about the length of the PSA.

"I thought the people ragging on her at the end were faking it. It could have been more realistic." [OM]

One group of older men resented the "authoritarian" tone (lecturing) of the PSA and the barrage of questions aimed at the woman who had caused the accident.

"You don't want to be harassed while you're watching television." [OM]

"I felt like I was being preached to. " [OM]

During this PSA, the women in several groups began to question why all of the PSAs included women drivers or featured women in some negative way. In two groups, women discussed their perceptions that most safe-driving ads target men. One older woman joked, "I didn't know teenage girls drove!" One woman was sensitive to the accidents or incidents having been caused by women and said, "It's so stereotypical to show women drivers.... Men complain about women drivers and this reinforces it." 
"I've never seen this many ads geared toward women. I relate to [these] more [than to ads geared toward men]. The women are just like me, driving recklessly and speeding. It could be me." [OW]

\section{PSA \#4}

Theme: Endorsement or Normative Appeal

Topic: Seatbelt Non-Use

Title: $\quad$ "Vince and Larry ${ }^{\mathrm{SM}}$

"Vince and Larry" 1985 U.S. DOT

The crash-test dummies are used to show the importance of using seatbelts. The two engage in a little repartee, with one telling the other, "Hey, we don't wear seatbelts. We're dummies." One dummy puts salt on the steering wheel and says, "I've been eating a lot of these lately." The car accelerates toward a target on a wall and the dummies can be heard yelling, "Whoaa!!" before impact. The tag line says, "Don't be a dummy. Buckle Your Safety Belt."

The "Vince and Larry"s" PSA, one of a series, promotes seatbelt use. There are several aspects to the motivational theme or appeal of the PSA. One is normative, with the implication that the viewer should emulate sensible people who use seatbelts (rather than "dummies" who don't), which is also an appeal to intelligence and perhaps a positive self-image. Another is informational, in that the PSA provides a reminder that seatbelts are protective. Another is a kind of endorsement, since Vince and Larry have become public figures of a sort. Finally, the PSA uses humor, though this is more a device to gain and keep attention than a means of influence.

With some exceptions, men and women responded quite differently.

After viewing the PSA, men often chuckled or laughed out loud. Although most women smiled and a few giggled, their reactions were not as dramatically positive as were the men's.

These response differences seemed to be very telling about what appeals to men and women. While men discussed the PSA's success as being both entertaining and informative, women said the humorous approach was inappropriate for conveying a serious message.

"It's entertaining. You listen to everything they said. " [YM]

"Entertaining, fun, but you get the message." [YM] 
"That one in particular, there's humor with it but there's a serious message. You're not going to go to the remote control and turn it off. It's entertaining, but it has a message. " [OM]

"I'd chuck that one, it's too cute. " [OW]

"Dummies are the most fun to watch, but the breaking-glass face [PSA \#2] was most effective.... Not being a dummy isn't the most important thing, not getting your face smashed in really comes home." [OM]

"As far as the dummies, it's good for children because children can relate to that. "[YW]

"I'm not big on those commercials....To get a point across about something [so serious] you need something serious to get it across because people are ignorant." [YW]

A few women were aware that crash-test dummies are sold as toys. All disapproved of this commercialization of television characters for teaching their children about traffic safety. In selling crash-test dummies as toys, women viewers believe that the joking tone of the series is highlighted, to the detriment of its important messages.

"Everybody would watch it....But when my kids got those toys [the crashtest dummies], it blew it out of the water for me. " [YW]

"It makes me sick that they're selling these [dummies] as toys. " [YW]

"My kids look at it as a joke. And they're dolls in stores now. It's not realistic to them. It's cute. It doesn't hit home. " [YW]

"Kids don't get the message because it's a joke. " [YW]

Women said a humorous approach simply did not work in conveying a serious message.

"It'd catch my attention, but after that, it would be gone. " [YW]

"It's entertaining...but with things like that, you need more a fear or motivation and it doesn't provide it." [YW] 
Men suggested the PSA should show the effect of crashing into the wall. When asked if showing the consequences of a crash would make the PSA more effective, women said it would.

"The car should hit the wall. You need to jolt people into buckling up." [YM]

"We need to see the consequences for something to click. " [YM]

Interestingly, participants were more attuned to the gender of the crash-test dummies than they were to the gender of live actors. Women suggested using a female dummy; some recommended using children and infant dummies as well to make the PSA more appealing to all viewers. One younger man suggested using children in the PSAs because "children have an impact on men (fathers)."

A few participants suggested these PSAs had overstayed their welcome and that they had become so popular and pervasive that it was easy to ignore them.

"When I see these ads, I know it means buckle up so I don't listen." [OW]

"I've seen so many of these, I wouldn't pay attention. I've got the message already. " [YW]

\section{PSA \#5}

Theme: $\quad$ Financial Costs

Topic: $\quad$ Speeding

Title: $\quad$ "Speeding Can Wreck Your Day"

A dashboard that resembles a pinball or video arcade scoreboard display is shown toting up the fines for speeding. As the speedometer increases, so too does the dashboard's amount for a speeding ticket. While the fine escalates, another meter shows the cost of insurance premiums rising and a sign flashes, "Tilt." The tag line says, "Speeding can wreck your day."

Most participants responded favorably, perhaps because the ongoing recession has made people focus on their financial well-being. As the adage says, "Money 
talks." In the case of this PSA, money as an incentive not to speed seemed an effective approach for both sexes and all ages.

Many participants did not realize that speeding tickets and points on driver's licenses are associated with higher insurance premiums. This was true for the men and the women.

"It never crossed my mind that my insurance would be affected by speeding tickets. " [OW]

Some participants whose premiums had increased said the PSA reinforced what they already knew.

"I got two really expensive tickets, $\$ 250$ each, and had to appear in court. So I know it's expensive." [YM]

Some participants said people would be less inclined to speed if they were more aware of the higher insurance premiums associated with speeding tickets.

"The first part [of the PSA] was not effective. I'd see how much I can get away with. But the insurance part did [affect me]. " [YM]

"[It] reinforces the habit that you need to keep your eye either on your rear-view mirror or on your speedometer. " [OW]

"Not enough commercials tied in with this...to show what happens to your insurance costs, that you're going to have to walk because you can't get insurance. " [OM]

The ages of men and women participating in the focus groups ranged from 25 to 59. There was general agreement that PSAs stressing the financial costs of traffic violations would be more effective with them than with younger drivers, who they said often have no real financial obligations and who may not even pay for the maintenance of their own cars.

"Our age group would understand this consequence more than younger drivers. " [YM]

"I don't think they can relate to actually having to pay for something. Our age group would understand that more. " [YM] 
Others believed the financial costs would only work as an incentive for the person in the family who controls the pocketbook. One man began to suggest that the cost-impact theme would be more relevant to men, whom many people yet consider to be the primary breadwinners in most families. However, the participant seemed uncomfortable saying this.

"[It has] a bigger impact on men...I guess in the majority of families....I'm not sure. " [OM]

Several participants said the speeding fines and increased insurance premiums weren't appropriate incentives. Women mentioned the physical dangers of speeding as being greater and more important than the financial penalties.

"When I think about speeding I don't think about fines, I think somebody is going to kill somebody. " [YW]

"Some people aren't scared enough about getting themselves killed." [OW]

"Other [PSAs] showed more drastic consequences. " [YW]

Younger women said the greatest incentive not to speed is to avoid the humiliation of being pulled over.

"I didn't care about the money aspect, that's not a big deal, but the humiliation of being pulled over and realizing that I was actually breaking the law [would affect me]. " [YW]

"Humiliation is really embarrassing. " [YW]

Some female participants said the PSA targeted men because of its pinball-game approach.

"I think it's a man's commercial--the pinball appeal. When it says tilt. All my brothers, they all play pinball, and when it [the PSA] says tilt, that would immediately catch them." [YW]

"It reminded me of a pinball machine and I can associate that more with men than with women." [OW] 
Views regarding the effectiveness of the "financial cost" theme seemed somewhat contradictory, but this may have been a function of the amount of money involved. Some participants who downplayed the importance of financial cost as a deterrent to speeding (when they were thinking only of fines) changed their minds when the cost of higher insurance premiums was also taken into account. At least in these cases, a subjective threshold existed: costs below this threshold could be ignored, but those above it had to be taken seriously.

It should also be noted that this PSA was viewed after others that dealt with injury and disfigurement. By contrast, fines or other financial costs may have seemed a relatively minor concern.

Both the male and female participants suggested other ways to illustrate the costs of speeding such as what might have been purchased with money used for speeding fines: Some female participants suggested showing new shoes or clothes, some men said to show tickets for ball games. One participant recommended that hospital costs resulting from speed-related crashes should be shown.

"Add a hospital bill, lost time from work, car-repair costs. There are other monetary consequences than car insurance. " [YW]

"I think these days everybody's attention is attracted when it comes to money....You don't want to put out money and get nothing in return." [OW]

"Equate the monetary loss to something else, like tickets to a ball game, [other things] you could spend your money on. " [YM]

"Next to the price amount for the fine, it could also say, 'A pair of nice shoes,' and show you in real terms. " [OW]

In one group of younger women, the PSA triggered a discussion about whether men or women are the worst drivers. Women apparently do not perceive themselves as taking risks or being aggressive when behind the wheel.

"Men speed more than women. They're more obnoxious. They're more aggressive by nature. They've got the money so [they'll say], 'I'll just pay the ticket and I can get where I'm going. Hurry up, write me the ticket, they say. Who cares?' Men have the money. " [YW] 


\section{PSA \#6}

\section{Theme: Personal Responsibility/Guilt/Love Topic: $\quad$ Drinking and Driving Title: "Mike"}

The PSA opens with a close-up on a floral arrangement that is not traditionally funereal and almost resembles a bridal bouquet. As the camera pulls back and more of the scene is revealed, we see that the flowers are placed on a tombstone on which the name "Mike Seymour" appears. An older, motherly voice is heard asking someone about a date. A young woman responds sadly that it was okay but "he wasn't Mike." The younger person then laments about what she might have done to take the keys from her boyfriend, Mike. Once this scene ends, we see two wine glasses being struck together and hear the tag line, "Friends don't let friends drive drunk."

Most male participants said this PSA turned them off almost immediately; they couldn't get to their television's remote control quickly enough "to change the channel." Women, however, were touched by the PSA and were sympathetic to most of its points. Some women did have problems with the voice of the younger speaker, whom they described as "insincere." Men just called her "sappy."

"[It] makes me want to cry. Definitely gets you where you live." [YW]

"[It was] good. I liked the fact that it got me by the gut." [YW]

"[It had] a powerful and clear message from the minute it started." [OW]

A few younger men liked the PSA.

"It was a grabber." [YM]

"I loved the commercial....Did grab my attention, hook, line, and sinker. " [YM]

Many older male participants--and a few younger ones--had almost the reverse reaction and disliked the PSA. Their comments centered on the production itself. Many did not like how this PSA was executed. They were put off by the graveyard scene, the "syrupy" female voiceover, and all the flowers. 
"Too much time focusing on flowers. I'd have flipped the channel." [YM]

"I would have changed it the minute I saw the flowers and heard the voice. " [YM]

"It was too bland all the way up to the end of it [when the two glasses crash]. It was just flat." [OM]

"Good plan, poor execution. The dialogue was really sappy. The voices were really syrupy. " [OM]

"Slow starting...poor execution. " [OM]

"Another soap ad, I'd think. " [OM]

"Too morose, voices too sappy." [OM]

"Where's my remote control?" [OM]

"Time to jump up to the refrigerator." [OM]

Men were, however, attracted by the image of two wine glasses being crashed together. Some suggested making this the beginning of the commercial to attract viewers' attention.

Most viewers believed the PSA targeted a younger audience and was not effective for people in their own age groups.

"Intended for a younger audience. " [YM]

In every group, the PSA and the message, "Friends don't let friends drive drunk," prompted discussions about how one should go about taking the keys from a friend who has had too much to drink. One older man described hiding keys from friends to force them to sleep it off at his house; a younger man described how he had disabled his brother's car.

Most participants said it is extremely difficult to actually take keys from someone who has had too much to drink. Several asked that PSAs be created to show how to accomplish this. 
"[We need] instructions on ways to take the keys. If a woman [wants to take] keys from a belligerent man, how does she address the situation?" [YM]

"It's easier to sit and watch [someone drive drunk] than to be in a situation [of taking keys] where you feel intimidated or you don't want to ruin the evening. " [OW]

"[Drunk] people are stubborn. It's an ego thing. " [YW]

One man said he would prefer to see themes that say, "You drink, you drive, you die."

\section{PSA \#7}

Theme: Personal Responsibility/Friendship

Topic: $\quad$ Seatbelt Non-Use

Title: $\quad$ "Project Lifesaver: Snap It Up"

The camera angle focuses almost entirely on the lower part of a car as two men get into it and prepare to drive off after playing tennis. The men are heard talking about the game and a new tennis racket. The driver then tells his passenger to put on his seatbelt. Conversation and a minor argument ensue as the friend hesitates to put on his seatbelt. The driver refuses to start the car and mentions that his passenger better buckle up if he ever wants to beat him at tennis again.

Many men found the theme or approach used in this PSA overbearing and felt it was directed to men who were more "macho" than themselves. Although the PSA showed only men, women in the groups related the message to instances in their own lives when they had tried to convince passengers to buckle up. For example, one woman described her frustration at being unable to convince her elderly parents to use seatbelts. Another mentioned a male passenger who refused to fasten his seatbelt.

This PSA offered them two specific actions that can be taken in such circumstances: refuse to start the car until everyone is belted in, and use a dare or challenge that conveys elements of humor, competitiveness, and personal concern or caring. 
"[Next time] I will be more adamant....[The PSA] makes you feel guilty for not being more forceful. [It] shows you can push it and still be friends. " [OW]

"It made me feel like I could do that too." [OW]

"It showed people how to handle the situation." [YW]

Several men described having been in life-threatening accidents in which their lives were spared because they had been wearing seatbelts. For these viewers, this PSA reinforced their belief in the usefulness of seatbelts.

"I had a Volkswagen go over the top of my car a couple of years ago. And the individual did not have a seatbelt on and I did. It's very important." [YM]

"I'm the guy who says, 'If you don't put on a seatbelt, walk buddy!'" [YM]

Other men, however, thought the PSA was "obnoxious," although one noted, "In a certain setting you might need to be obnoxious." Many men also suggested PSAs emphasize the importance of making rear-seat passengers use seatbelts as well.

Men and women found the conversation about tennis distracting; for some viewers, this conversation made the talk about the seatbelt difficult to understand. One woman remarked it was difficult to tell whether or not the driver and his passenger were actually buckled up. One woman did not care for the angles shot, such as the focus on the door and the elimination of faces.

"If someone takes a picture and they cut off your head, you throw the picture in the trash." [OW]

"Should be obvious that the guy puts his seatbelt on." [OW]

Some women suggested making the PSA more appealing to women by showing two women in a similar situation, or by showing a couple going out on a date or for an evening. Several participants felt the PSA would have been more effective had it shown the actors' faces. 


\section{Participant Suggestions for Appealing to Men and Women}

Participants were asked how they would advise producers to improve PSA effectiveness in reaching men and women.

\section{Use Realistic Settings and Common/Typical Situations}

Male and female participants said the production must be day-to-day realistic and relevant to the target audience. Both sexes and age groups asked for PSAs that are direct and brief.

"Use situations men find themselves in--sporting events, being with their kids, dating. " [YM]

"[You] need all kinds [of ads]. For some people, money hits home more than the idea of getting killed. Each kind will hit different people. Some will hit kids, some [will hit] older or younger [audiences].... " [OW]

\section{Use Persons of Appropriate Gender and Age}

Men voiced a preference for messages delivered by other men. One younger man said the speaker could be "Any man, a regular guy who's been through it." Another said:

"I'd show a family man who lost his wife in a car crash, or lost his kids. As a man that would hit me hard, being left alone to raise my kids." [YM]

Women voiced less preference about the sex of the presenter but regarded age as very important. Age of the speaker was also an important consideration for men.

"IIf an older man is] telling me something, I have to look at it more indepth." [YM]

"A college-aged kid wouldn't appeal to me. I'd just be glad I survived [that age myself]. " [YM] 


\section{Demonstrate Effective Interventions and Other Actions}

People would also like to see PSAs that not only tell them what not to do, but what to do in some situations, such as taking keys from a driver who has had too much to drink.

"Show the actual, socially acceptable way to do it. " [OM]

\section{E. Communications Styles and Behavior}

Men in both age groups were less likely to talk about their personal lives or to describe in great detail their own driving experiences. Men tended to be more reserved and to speak in more general terms. For the most part, however, when the discussions ended, an observer would have been hard-pressed to tell which men were married and had children or which men were feeling the dual pressures of family and career.

There were some exceptions to this. Two men described at length their reactions to having received citations for drunk driving: the financial burden, the mandatory classes, and their changes in behavior. One reported that he has been sober for six years as a result. Some men described crashes in which they had been involved.

Men followed the ground rules for focus group discussion, seldom interrupting each other or speaking among themselves. Occasionally, men would reinforce what other participants had said. The men were very polite and deferential. (This behavior may have been the result of there having been a female moderator.)

Unlike the men, the women participants were much more self-disclosing and were more likely to interrupt each other or to reinforce what other participants had said. By the end of each session, many women had disclosed a great deal about their relationships with friends, husbands, and children. In addition, women may have been more open in sharing information with regard to driving aggressively or drinking and driving. Men may be more hesitant to disclose specifics about driving behaviors.

Although attentiveness to messages was not a focus of the study, one peripheral but potentially useful finding was that men tended to be much less patient or tolerant than women with regard to television PSAs they disliked. Men's reactions in the groups (and their comments about the PSAs) indicated that they often decided within the first few seconds whether they would watch a PSA or use the remote control to try 
another channel; women said they were usually willing to view a PSA in its entirety. Producers and advertisers have known for some time that the first few seconds of a commercial can determine whether or not viewers will watch it; the reactions observed in this study suggest that this is especially true for men. 


\section{Conclusions}

This section presents conclusions drawn from this study. Recommendations regarding future research and the development of safety campaign materials are presented in Chapter V.

Findings are presented in the following sequence: driving habits and attitudes, responses to selected PSAs, and communications styles. This matches the sequence of topical discussions in the focus groups, a sequence chosen on the premise that individual circumstances related to driving form the context in which safety messages are interpreted. In this area as in others, how people perceive and react to PSAs and commercials depends largely on their perceptions of the personal relevance and appropriateness of the messages conveyed.

\section{A. Similarities Between Men and Women}

1. In terms of driving attitudes and habits, men and women in the groups:

a. Were concerned about their safety in automobiles and believe it may be compromised by other drivers. Many participants indicated that for them the experience of driving has deteriorated in recent years--that contemplation of a drive has changed from pleasurable anticipation to dread. (This feeling should be taken into account in designing safety advertising, since it influences the way messages will be perceived and interpreted.) Many drivers cited speeding, running red lights, and failure to stop at stop signs as examples of risks other drivers frequently take. Older drivers, however, also included violations such as running yellow lights, using horns for non-emergencies, and passing on the wrong side.

b. Sometimes found driving relaxing, an opportunity to be alone and to think. Most of the men and many of the older women described driving, especially for long trips, as relaxing. Younger women more often described it as a frustrating and necessary evil. Although all drivers expressed frustration about traffic congestion and the poor behavior of fellow drivers, younger women seemed particularly frustrated. While other participants mentioned that they find long drives relaxing, or view driving alone as a time to think, younger women seem to feel, when they are behind the wheel, that they are at war with other drivers. 
c. Drive more cautiously when children are in the car. Drivers are responsible for the safety of all passengers; with children, however, drivers seem to feel this responsibility more acutely and adjust their driving accordingly. For example, drivers will be less aggressive and less likely to speed when they have children with them.

d. Admitted to venting the day's stresses and frustrations by driving more recklessly. Most participants spoke of having a bad day at work, trouble with children, or arguments with friends. In addition, many people spend a great deal of time commuting on congested highways, transporting children from one location to the next, and juggling the dual duties of home and family. Taken separately, any of these elements can be stressful; taken together, they can create a stress overload. Many participants cited stress as contributing to speeding or driving recklessly on occasion.

\section{Discussions about traffic safety PSAs revealed that men and women in the groups:}

a. Were aware of advertising strategies and marketing techniques. Although the recruitment process screened out persons who worked in advertising or marketing, a number of people in the groups were able to discuss production values and seemed comfortable talking about presentation styles, spokespersons, messages, and appeals. They were aware that advertisers often identify specific target audiences and tailor messages to them. The comments by both men and women regarding the poor quality of some PSAs indicated that they are unlikely to respond favorably to PSAs that are not well produced.

\section{b. Said they would like specific advice on how to deal with certain} situations, especially with regard to influencing friends' unsafe driving behaviors. Most participants were familiar with the "Friends Don't Let Friends Drive Drunk" campaign, but said that while they agreed with this in theory, they often did not know how to apply it. How, women asked, could they take the keys from a male driver who had become drunk and belligerent? Some participants offered their own solutions, such as hiding car keys, but most asked to see messages that would give them practical tips on how to prevent drunken friends from driving.

c. Felt the age of the presenter in a PSA should be close to their own. Often, PSAs may rely on young people to deliver a range of traffic safety messages that are intended to reach a wide audience. All participants, however, said they were more likely to pay attention to a message delivered by a peer, and not by a much younger or much older spokesperson. 
d. Wanted to see realism and personal relevance in PSAs about traffic safety. Participants said they would like to see typical aspects of their own lives and driving experiences reflected in PSAs. For example, men said they preferred messages that included common experiences, such as attending ball games or going out for drinks after work. Women said they wanted to see other women engaged in ordinary activities, such as attending a business meeting, shopping, or other social functions. PSAs that imbed messages in portrayals of everyday experiences would have the potential to speak directly to viewers and model appropriate behaviors for them. (By contrast, most people probably have difficulty relating to PSAs with unreal or extraordinary scenes--those using animation, science-fiction settings, vehicle crash labs, and so on.)

e. Responded to appeals that hit drivers in the wallet or the pocketbook. Both sexes appreciated the PSA describing the financial penalties associated with speeding. Participants said "money talks," and all responded favorably to a message that revolved around this theme. Most participants believed such a message would be effective for any viewer, regardless of age or sex.

\section{B. Differences Between Men and Women}

Differences between men and women emerged in discussions of driving habits and behaviors, responses to PSAs, and communications styles.

\section{In terms of driving attitudes and habits:}

a. Many younger women described themselves as aggressive or assertive drivers, sometimes engaging in direct confrontation with other drivers. Younger men described themselves as becoming more cautious drivers. Several young women boasted about their ability to weave in and out of traffic, although they often qualified these statements by saying, "But I'm a safe driver." Young women described occasions in which they have actually confronted other drivers when those drivers' errors threatened the women's safety or interfered with their travel. (These women said they drive mostly in neighborhoods that would generally be considered "safe." The behavior they described might be much less common in areas where they would feel at risk in confronting other drivers.)

b. Women often cited the stress of driving with children, although men rarely mentioned this. Younger women repeatedly pointed to the distractions created by child passengers. Only a few men noted that having children in the car can contribute to a stressful driving situation. 
c. Older women were more attuned than older men to the effects of the aging process on their driving skills. Older women noted that changes in their eyesight, especially as they approached middle age, made night driving difficult. Older men made no mention of physical impediments to their skills as drivers.

2. In terms of the specific PSAs presented, the following differences emerged:

a. Women in the groups responded more favorably to emotional appeals than did men. Where women were more attuned to the emotional toll to be paid as a result of a serious traffic safety violation being committed, men seemed to be more attuned to the physical or financial consequences. Men were more concerned that a person might be injured or that a fine would have to be paid. Women often discussed the emotional ramifications of an accident, such as the pain of losing a loved one to a drunk driver. Most women, for example, liked a PSA in which a young girl talks to an older woman about how much she misses her friend and what she might have done to prevent her friend from drinking and driving. Women said they could relate to some aspect of the PSA, often in their own roles as mothers. Many of the male participants, however, disliked the "sappy" approach. They thought the overall approach was not effective. Some even remarked that the voices of the actresses were "too sweet."

b. Female participants felt humorous approaches detracted from the seriousness of the material being presented while many of the male participants preferred this approach. After viewing a humorous PSA that featured the crash-test dummies, men laughed out loud and admired the cleverness and intelligence of the PSA. Men picked up on the nuances of the ad, such as the dummy sprinkling salt on the steering wheel. Women smiled or giggled, then remarked that the ad would appeal to their children. Several women expressed reservations about taking a humorous approach to a serious issue. Few men objected. It should be noted that the fact that the use of humor to convey a serious message appealed to men was contrary to what was found in the 1978-1986 study by the National Heart, Lung, and Blood Institute regarding high blood pressure cited earlier in this report.

c. Female participants generally had no objections to PSAs with an explicit exhortation to take a given action, while most of the men found this approach authoritarian or "preachy." Most men in the groups said that one PSA, in which a woman driver hits a pedestrian and then must confront the accusations of angry onlookers, preached at them. These male participants resented the series of hardhitting questions from onlookers. Some males in these groups also criticized the PSA where a male driver asked his tennis partner (passenger) to buckle his seatbelt because 
the driver's tone was too "authoritarian." The female participants did not seem to notice this tone in these or any other PSAs shown.

d. The female participants were not as concerned about production values as the men in the groups. After viewing a PSA, many of the male participants remarked about the quality of the production. The women, with the exception of one group of older women drivers, more often responded initially to the content and context of the PSAs. The male participants seemed more concerned with camera angles, black-and-white filming, and the professional quality of each production.

e. Women were more likely to say they would watch an entire PSA, while many men said they would have used the television's remote control to change the channel. If a PSA did not hold immediate appeal, men often said they would "hit the remote" or "raid the refrigerator." Women were more inclined to keep watching.

f. Women perceived PSA information as relevant to others in their lives like parents, children, friends, as well as to themselves. Men were more likely to assume that if the information was not geared specifically to them, it was not useful. (Some men said certain PSAs would be effective for their teenaged children, but these were the exceptions.) After viewing a PSA, women frequently remarked they could see themselves, their husbands, or their children in some aspect of the PSA, such as racing to get to work, or encouraging someone to wear a seatbelt, or wondering how to keep teenage children from drinking and driving. Men seldom mentioned such connections to others in their lives.

g. Women derived meaning from every PSA regardless of its target audience or the sex of the spokesperson. For example, women viewed the "Project Lifesaver" PSA (illustrating techniques for drivers asking passengers to buckle their seatbelts) as an educational one, stating that it had given them a way to talk to their husbands or friends about buckling up. Some men dismissed the same PSA as targeting only "macho" men and thus having no relevance to their own lives.

h. Women were sensitive to the potential for negative gender stereotyping in traffic safety PSAs. Many women remarked on the prevalence of women in the PSAs that were shown. They noted that they had seldom seen traffic safety PSAs featuring women drivers and were happy to see women included. However, they expressed concern that showing women causing crashes or as poor drivers would perpetuate negative stereotypes. They pointed out that it would be helpful to have some PSAs showing women doing the right thing behind the wheel. 
Although a number of differences between men and women were noted in the groups, they were based on particular circumstances (as well as on observation and inference), and therefore should be interpreted with caution. As noted, both men's and women's groups had a woman moderator, and this may have influenced to some extent the differences of content and tone observed in their comments. Given the flexibility of focus-group questioning and the natural differences among groups in the flow of the discussions, it is inevitable that certain issues would be explored in more detail in some groups than in others.

That said, it still seems reasonable and fairly important to note that women may have found more ads appealing, even those aimed at men and showing only men, and particularly when the emphasis was on friendships or other personal relationships. This inference is based on reactions observed in the groups, but it is also consistent with findings from the background review and other information obtained in this report. 


\section{Recommendations}

Information from this report has implications for future qualitative and quantitative analyses. Recommendations in these areas stem from information collected through the background review and interviews with communications experts and officials from the automobile industry, as well as from the findings and conclusions of the focus groups. Quite limited background information about response differences by gender led staff to reflect upon what future activities might be conducted to obtain additional information on gender-related response differences. These activities are included among the recommendations in this chapter's final section, "Additional Study." Men and women should be distinguished in both qualitative and quantitative studies to further identify and analyze response similarities and differences.

The conclusions in this report should be regarded as tentative for several reasons. The study involved a limited population--a total of only 60 people, ranging in age from 25 to 59, and all living in a single metropolitan area. There was some diversity in terms of ethnicity, occupation, educational attainment, marital status, and other factors, but the small number of people imposed obvious limits on the range of differences. Because this kind of study does not involve a representative national sample of 1,000 or more respondents, the findings may not be applicable to the population as a whole. Although these qualifications are important, the following recommendations still provide useful ideas for further investigation of the problems of female-crash involvement and injury and possible gender-based differences in response to safety communications.

\section{A. Recommendations Regarding Qualitative Studies}

\section{Conduct Additional Background Reviews}

The current project focused on gender differences in response to traffic safety programs, public health programs, commercial advertising in the automotive and tobacco industry, and academic research. A review of consumer risk-taking, such as insurance, banking, retirement planning, financial investment, and credit card acquisition, might reveal additional gender-based differences. (Much of this information might be proprietary, but an exploratory effort is warranted.) 


\section{Conduct Gender-Based Focus Groups With a Wider Range of Respondents}

Age bears relationship to crashes and potential interventions. Crash-related statistics and trends in television and radio programming suggest it would be helpful to conduct additional groups with both younger and older drivers than the participants in this study.

a. Young drivers. Focus groups with men and women between the ages of 18 and 25 would be very helpful in evaluating response differences and designing future programs. Much of the traffic safety PI\&E material now in use targets males in this age range. Younger women are represented in crash statistics and there now may be a need for materials directed to them. Additional studies of young drivers might also reveal information that could be used to develop alternative communications products, such as driver training videos aimed at reaching inexperienced and newly licensed drivers.

b. Older drivers. Groups with older drivers need to be included because America's driving population is aging. It is important to learn more about the special needs of this group and how those needs differ by sex. Older drivers are generally more likely to die from injuries they sustain in crashes, especially frail, older women. Older women also outnumber older men and have less cumulative driving experience. Therefore, it is imperative that this group of drivers be reached with effective and appropriate materials.

Learning the reasons for traffic deaths among women or the characteristics of the victims from focus groups would be helpful in designing more effective interventions.

c. Women who have been involved in crashes. Such groups might provide data on some of the personal characteristics associated with crashes, such as driver fatigue, stress, inexperience, risk-taking propensity, and specific gaps in driving skill or knowledge. A comparison of the profiles of women involved in crashes and men involved in crashes would be instructive. If clear differences emerged, these would aid in shaping separate programs for men and women; if the profiles of men and women were quite similar, this would support the continuation of programs undifferentiated by gender.

d. Women who are at risk for crash involvement. If the study cited above were to find a set of personal characteristics associated with crash risk, women with similar profiles could be identified and intervention efforts could be undertaken prior 
to actual crash experience. Women's reactions to different approaches could provide an early look at the potential effectiveness of various interventions.

\section{Collect Information on Receptivity of At-Risk Populations}

Many at-risk drivers, both female and male, may have psychological, social, or economic problems that may make it unlikely that they will be influenced by multimedia campaigns alone. Receptivity data could be used to target messages first to receptive groups, in order to explore ways to effectively influence some of these hardto-reach audiences.

\section{Additional Research}

Other future focus group projects might incorporate the following elements:

a. Evaluate gender-based differences in response to non-PSA materials used in other public sector and commercial campaigns. This study used only television PSAs; similar studies could use radio PSAs, print advertisements, pamphlets, videotapes, driver-education and DMV manuals, dealer showroom materials, vehicle owners' manuals and orientation videos, and other kinds of materials. The materials to be tested should include both gender-neutral and genderspecific messages in a variety of formats.

Delivery mechanisms or channels not commonly used by traffic safety programs include interviews on television and radio talk shows, safety messages within movies and television programs, and shows on local cable television systems. These and others deserve trial uses with appraisals of results.

b. Examine gender differences in perceptions of common traffic safety vocabulary. In developing programs, planners must understand how males and females perceive and process information about traffic safety at the most basic level-defining vocabulary phrases such as "drunk driving" and "speeding." Malfetti found that young men and women defined "speeding" and "drunk driving" differently. ${ }^{22}$ We need to know what other traffic safety words men and women of various target populations use differently and how. (This issue could not be addressed in the current

${ }^{22}$ Basch, C.E., De Cicco, I.M., \& Malfetti, J.L. (1987). Perceptions, Attitudes, Motivations, and Behaviors of Drivers 18 to 22 Years Old. Safety Research and Education Project, Teachers College, Columbia University. 
project because the issue emerged after the focus group materials (including the moderator's guide) had been developed.)

c. Explore more fully other potentially effective ways of reaching women with traffic safety messages. For example, it is important to know how women's perceived role responsibilities shape their responses to traffic safety messages? What proportion feel responsible for the health and safety of others? What approaches might work to reach people who perceive no such responsibility? What kinds of actors and settings would women regard as realistic?

d. Explore other safety topics, themes, and approaches. Future projects could deal with more topics than drinking and driving, speeding, and non-use of seatbelts. They might also look at other thematic variations such as motivations for safe driving practices. Suggestions include:

- Fear, wellness, and self-preservation themes.

- Testimonial approaches based on victim-impact, such as disabled survivors, families of people killed or injured, and drivers who have killed or injured others.

- Other visual and aural images of the physical, mental, emotional, and financial tolls of crashes.

- Messages promoting self-protective behaviors, some of which are reinforced by legal sanctions (e.g., seatbelts) and others that are not.

- Instructional approaches that demonstrate strategies for influencing safe practices of other drivers such as modeling how friends might not let friends drive drunk.

e. Examine gender perceptions using carefully tailored messages and production. Instead of "off-the-shelf" television PSAs, the next step would be to produce and test new materials using systematic variations in motivational appeals, production style, spokesperson characteristics, and other factors based on audience reactions. 


\section{B. Recommendations Regarding Quantitative Studies}

The background review revealed that few data are available to explain why women drivers are involved in fatal crashes. Without such data, communications program planners cannot identify target audiences and priority-crash situations--critical steps in the development of safety messages. Further quantitative analyses are necessary in a number of areas. As stated earlier, these recommended study designs should include men, as well as women.

\section{Collect Crash Trend Data}

Besides data about age and sex trends in crash fatalities, gender-specific information on other variables may tell a more revealing story about crash involvement. Some factors to consider:

a. Characteristics of single- and multi-vehicle crashes and the types of crashes and cars involved. This would include information from police accident reports such as road designs and conditions, geographic location, timing (e.g., day, night, rush hour), occupant seating positions, seatbelt and air bag usage, and cause of crash.

b. Characteristics of drivers involved in crashes, including marital status, employment status, prior traffic violations, race, and socioeconomic variables.

c. Elements contributing to the crash. A wish-list of potential information would include data that are difficult to collect but extremely important for exploratory research, such as alcohol impairment and speed, risk-taking behavior, aggressiveness, driver stress, poor knowledge of the "rules of the road," unfamiliarity with the road, driver fatigue, inattention, and poor driving skills.

d. Crash injuries sustained, including their nature and extent of physical and psychological injuries, prognosis for long-term recovery, and financial costs. disposition.

e. Insurance coverage (or non-coverage), claims filed, and claims

These data would be used to highlight priorities for future program planning, indicating the message points that might well be developed to reach and influence men and women. 


\section{Estimate Message Receptivity}

Communicators need to statistically determine which target subgroup audiences of men and women are most receptive to traffic safety messages, i.e., perceive and respond behaviorally to messages and information. Combining information on personal and demographic characteristics might be helpful in distinguishing the subpopulations most likely to accept traffic safety messages.

\section{Plan for Gender Analyses}

Most past reports examined for this project did not differentiate information by gender. The collection and analysis of gender-related data should be considered in planning future studies.

\section{Program Planning}

The use of gender-specific market segmentation techniques should be expanded to define and reach at-risk, responsive subpopulations. A market analysis could be conducted that would ascertain the knowledge, attitudes, and behaviors of specific cohorts of men and women drivers. The characteristics of men and women who are most represented in crashes should be identified. Then priorities can be established to indicate which of these subgroups must and can be reached.

Once these characteristics have been identified and target audiences selected, it is appropriate to use available data on media usage in choosing the most efficient placements for materials. For example, the Annual Study of Media and Markets published by the Simmons Market Research Bureau is based on interviews with a national probability sample of 19,000 adults each year.

The fact that government agencies cannot buy advertising time or space greatly limits their ability to control advertising placements. However, information about media usage can still be helpful in seeking to obtain adequate exposure for materials. Rather than sending a given radio PSA to all stations, for example, it is far more efficient to send copies only to those with a format that appeals to the intended audience for the PSA--and far more likely to gain actual placements. At present, few safety agencies distribute materials selectively with regard to matching target audience profiles (by age, gender, income, etc.) with 12 standard radio formats, 18 major magazine categories, and 19 combinations of program type and day-part in television.

When targeting specific audiences, the following should be considered: 


\section{Target Audiences With Information Delivered By Age-Appropriate Persons}

Participants often expressed sensitivity to the age of actors in the PSAs shown and noted that they would, for example, pay little attention to an adult warning a teenager not to drink and drive. Participants said they are more likely to respond to or identify with people in their own age group with whom they might share experiences or perceptions, or people who are slightly older for whom they bear respect. Using persons appearing in PSAs who are age appropriate may entail additional production costs. Several versions may need to be produced and distributed differently to appropriate media.

\section{Show Persons Engaged in Real-Life Day-to-Day Situations}

Participants suggested that they would be more responsive to productions reflecting their own circumstances, e.g., middle-class people who work and meet the responsibilities of home, family, and society. Such productions would seem more relevant to their lives and should offer practical advice on how to become safer or better drivers.

\section{Educate Women About Their Risk of Involvement in Serious Crashes}

Many women believed men are at risk for crash involvement as a result of speeding and drinking and driving, but not women. Much work needs to be done to educate women to be more aware and sensitive to this risk.

\section{Develop Messages That Address the Needs and Problems of Women Drivers}

A safety campaign might offer tips on how to drive safely with child passengers or how to cope with diminished ability to drive at night. (Women audiences might be larger, but male drivers might incidentally benefit too.)

\section{Avoid Perpetuating Unfounded Stereotypes About Women as Poor Drivers}

Female participants were sensitive to their negative portrayal as drivers by the media and cautioned those who develop traffic safety PSAs not to reinforce these negative images. Messages should portray positive images of women and care should be taken to avoid condescension. 
60

\section{Additional Study}

In addition to recommendations derived directly from the project's background review and focus groups, the following areas emerged as a result of information gaps and merit further study.

\section{Determine Effective Communications Channels to Reach At-Risk Drivers}

Focus groups should be used to identify specific communications channels that at-risk, receptive drivers most often respond to when presented with traffic safety and health messages. Many drivers who are most at risk for crash involvement have other problems, such as alcohol addiction, that make successful traffic safety messages difficult to deliver or potentially very costly.

\section{Conduct Studies of Innovative Communications Channels}

Most health and safety information of a general nature is obtained through television, magazines, newspapers, and radio, while answers to specific questions are usually sought from health-care providers or from friends and relatives. Further emphasis on personal influence is clearly warranted.

Most safety messages have been distributed through the traditional mass media, with relatively few efforts to use alternative channels. These could consist of such avenues as information displayed in automobile dealer showrooms, physician's offices, or libraries. Projects that evaluate the effectiveness and efficiency of these and other alternative mechanisms for delivering safety messages deserve serious consideration. 


\section{APPENDICES}




\section{APPENDIX A}

\section{BIBLIOGRAPHY}

Arkin, E.B. (1987, February). Analysis of high blood pressure target audience and message test reports, 1978-1986. Unpublished report for National Heart, Lung, and Blood Institute.

Alreck, P.L., Settle, R.B., \& Belch, M.A. (1982). Who responds to 'gendered' ads, and how? Journal of Advertising Research, 22, pp. 25-31.

American Academy of Pediatrics. (1990, February). Don't Risk Your Child's Life! (brochure), Elk Grove Village, Illinois.

Basch, C.E., De Cicco, I.M., \& Malfetti, J.L. (1987). Perceptions, Attitudes, Motivations, and Behaviors of Drivers 18 to 22 Years Old. Safety Research and Education Project, Teachers College, Columbia University.

Beirness, D.J. (1989). Female Drivers in Canada: Trends in Accident Involvement. Women, Alcohol, Drugs and Traffic. Proceedings of the International Workshop, Stockholm, Sweden, 29-30 September, 1988.

Bellizzi, J. (1991, June 1). Gender positioning of a traditionally male dominant product. Journal of Advertising Research, 31, pp. 72.

Benson, S. \& Rund, C. (1983, July). Motivation of Restraint System Usage Among Specific Target Groups of Drivers and Passengers. Final report.

DOT/NHTSA, DTNH22-82R-07184.

Bern, S.L. (1982). Bern Sex-Role Inventory. California Consulting Psychological Press.

Berry, J. (1990, June 25). The many faces of Eve: New moms. AdWeek's Marketing Week, pp. 44-5.

Brock, F. (1990, June 25). The many faces of Eve: Blue/pink collars. AdWeek's Marketing Week, pp. 47-8.

Broughton, J. (1990). Casualty rates among car occupants. TRRL Research Report, RR 224, p. 27.

Buchanan, L. \& Reid, L.N. (1977). Women role portrayals in advertising messages as stimulus cues, a preliminary investigation. In G.E. Miracle (Ed.), Sharing for Understanding, Lansing, Michigan. American Academy of Advertising. 
Calspan Corp. (1975). Tri-level accident investigation study. Progress Report for Quarter No. 1, 1 January 1975 to 31 March 1975. Buffalo, New York.

Candler, J. (1986, September 15). Women and the auto market: Unlocking mystery surrounding consumer category. Advertising Age Special Report, pp. S-1, S-4, S-6.

. (1991, January 21). Woman car buyer--Don't call her a niche anymore. Advertising Age Special Report, pp. S-5-6.

Carli, L.L. (1989). Gender differences in interaction style and influence. Journal of Personality and Social Psychology, 56, pp. 565-76.

Centers for Disease Control. (1991). Executive summary from focus group study on reaching at-risk youth with HIV prevention mass media materials. Unpublished. Conducted by Communications Technologies.

Clark, L. (1988, April 4). Chevy, VW aim direct-mail campaign at women. Automotive News, p. 63.

Cleaver, J.Y. (1988, March 7). Lifestyle ads boost banks, insurers. Advertising Age Special Report: Marketing to Women, p. S-5.

Crancer, Jr., A. (1967). Accident and Violation Rates for Washington Drivers. Washington Dept. of Motor Vehicles, Olympia, Washington.

Curtindale, F. (1988, November). Marketing cars to women. American Demographics, pp. 29-31.

Debevec, K. \& Iyer, E. (1986). The influence of spokespersons in altering a product's gender image, implications for advertising effectiveness. Journal of Advertising, 15, pp. 12-20.

DeJong, W. \& Winsten, J.A. (1990). The Harvard Alcohol Project: A demonstration project to promote the use of the "designated driver." Proceedings, 11th International Conference on Alcohol, Drugs, and Traffic Safety. Chicago National Safety Council, 1990.

DeJoy, D.M. (1992). An examination of gender differences in traffic accident risk perception. Accident Analysis \& Prevention, 24(3), pp. 237-46.

Dignan, M., Bahnson, J., Sharp, P., et al. (1991). Implementation of mass media community health education: the Forsyth County Cervical Cancer Prevention Project. Health Education Research, 6, pp. 259-66. 
DuBrin, A.J. (1991). Sex and gender differences in tactics of influence. Psychological Reports, 68, pp. 635-46.

Duker, J.M. \& Tucker, Jr., L.R. (1977). Women's lib-ers' versus independent women: A study of preferences for women's roles in advertisements. Journal of Marketing Research, 14, pp. 469-75.

Erickson, J.E. (1988, March 7). It's tough to keep up with changes. Advertising Age Special Report: Marketing to Women, p. S-1.

Fehr, S.C. (1992, January 14). Dramatic increase in fatality rate for women puzzles analysts. The Washington Post, p. A7.

Fenigstein, A., Scheier, M.F., \& Buss, A.H. (1975). Public and private selfconsciousness: Assessment and theory. Journal of Consulting and Clinical Psychology, 43, pp. 522-27.

Flora, J.A. \& Wallack, L. (1990). Health promotion and mass media use: Translating research into practice. Health Education Research, 5, pp. 73-80.

Fortini, M.E. \& Perrine, M.W. (1989). Characteristics of the female drinking and driving, from Proceedings of the 11th International Conference on Alcohol, Drugs and Traffic Safety, October 24-27, 1989, Chicago, pp. 655-60.

Frederick/Schneiders, Inc. (1991, July). Focus group findings prepared for Center to Prevent Handgun Violence and American Academy of Pediatrics.

Freeman, L. (1986, September 15). Magazines study reader and advertiser needs. Advertising Age, p. S-8.

Freimuth, V.S., Stein, J.A., \& Kean, T.J. (1989). Searching for health information: The Cancer Information Service model. Philadelphia University of Pennsylvania Press.

Gould, S.J. (1987). Gender differences in advertising response and self-consciousness variables. Sex Roles: A Journal of Research, 16, pp. 215-25.

Gurin, D.B. (1981). Women's Future Travel, Driving, and Transit Use. Psychology of Women Quarterly, 6(1), pp. 72-84.

Harrison, W.A. (1986, April). Drink Driving Fatalities and Casualties in Victoria. Victoria Road Traffic Authority, HS-039 871. 
The Hearst Corporation. (1985). The American Woman's Knowledge of Health \& Physical Well-Being: A National Survey of Public Awareness and Personal Opinion. New York:Author.

Heiman, A. (1992, August 16). Gender fenders: Car comfort and safety for women. Richmond Times Dispatch.

Hidlebaugh, T.A. \& Richman, L.A. (1984). Motivation of restraint system usage among specific target groups of drivers and passengers. Final report. DOT/NHTSA Report No. DOT HS-806 579 Contract No. DTNH22-83-R-07243. July 1984.

Hildebrand, E.D., Wilson, F.R., \& Beirness, D.J. (1989). Special Groups, Proceedings of the Canadian Multidisciplinary Road Safety Conference VI. New Brunswick University Transportation Group.

Hollie, P.G. (1985, March 23). Segmented cigarette market. New York Times, pp. 29, 31 .

Horton, C. (1991, October 7). Honda's full plate. Advertising Age, p. 24.

Insurance Institute for Highway Safety. (1992). Crash problem on a per mile basis. Status Report, 27(11).

Iyer, E. \& Debevec, K. (1986). Gender stereotyping of products: Are products like people? In N. K. Maholtra \& J.M. Hawes (Eds.), Developments in Marketing Science, Atlanta Academy of Marketing Science.

Jaffe, L.J. (1989). The effect of positioning on the purchase probability of financial services among women with varying sex-role identities. In M.E. Goldberg, G. Gorn, \& R.W. Pollay (Eds.), Advances in Consumer Research, Vol. 17, Provo, Utah: Association for Consumer Research.

- (1991, June/July). Impact of positioning and sex-role identity on women's responses to advertising. Journal of Advertising Research, 31, pp. 57-64.

\& Berger. (1988). Impact on purchase intent of sex-role identity and product positioning. Psychology and Marketing, 5, pp. 259-71.

Johnson, J.D. \& Meischke, H. (1991b). Cancer information: Women's source and content preferences. Journal of Health Care Marketing, 11, pp. 37-44. 
Jones, I.S. (1975). The Role of Vehicle Handling in Accident Causation. Society of Automotive Engineers, SAE 750115.

. (1991a). Women's preferences for cancer information from specific communication channels. American Behavioral Scientist, 34, pp. 742-55.

KRC Research \& Consulting, Inc. (1991, June 4). Executive summary of findings from focus groups conducted for the American Academy of Pediatrics on promoting childhood immunization programs.

Kanungo, R. \& Johar, J. (1975). Effects of logos and human model characteristics in product advertisements. Canadian Journal of Behavioral Science, 7, pp. 127-38.

Kiley, D. (1988, March 7). Motorcycle marketers in drive to impress female segment. Adweek's Marketing Week, p. 2.

King, J.L. (1988, June 6). Ford folks, 200 women talk about buying cars. Automotive News, p. 43.

Krupka, L.R. \& Vener, A.M. (1983). Over-the-counter appetite suppressants containing phenylpropanolamine hydrochloride (PPA) and the young adult: Usage and perceived effectiveness. Journal of Drug Education, 13, pp. $141-52$.

Krupka, L.R., Vener, A.M. \& Richmond, G. (1990). Tobacco advertising in gender-oriented popular magazines. Journal of Drug Education, 20, pp. 15-28.

Kyes, K.B. (1990). The effect of a 'safer sex' film as mediated by erotophobia and gender on attitudes toward condoms. The Journal of Sex Research, 27, pp. 297-303.

Lammers, H.B. (1991). Moderating influence of self-monitoring and gender on responses to humorous advertising. The Journal of Social Psychology, 13, pp. 57-69.

Langer, J. (1987, August 28). A woman is still a woman, but a man now has his doubts. Marketing News.

Leigh, T.W., Rethans, A.J. \& Whitney, T.R. (1987). Role portrayals of women in advertising: Cognitive responses and advertising effectiveness. Journal of Advertising Research, 27, pp. 54-62. 
Levin, G. (1991, February). Cutler: Planning in an uncertain market. Advertising Age, p. 4.

Levy, L. (1990, May 28). Allstate led with air bags. Advertising Age, p. 28.

Lynker, J. (1992, August 21). Dealers will try Disney approach to client service. Washington Times, p. G1.

McGrath, J.C. (1991). Evaluating national health communication campaigns. American Behavioral Scientist, 34, pp. 652-65.

Mannering, F.L. (1991, July 18). Male/Female Driver Characteristics and Accident Risk: Some New Evidence. Paper, Department of Civil Engineering, University of Washington.

Mattera, J. (1990, May). Women and cars: On a roll. Glamour, pp. 254-59.

Mayhew, D.R., Warren, R.A., Simpson, H.M. \& Haas, G.C. (1981). Young Driver Accidents: Magnitude and Characteristics of the Problem. Traffic Injury Research Foundation of Canada.

Meyers-Levy, J. \& Sternthal, B. (1991). Gender differences in the use of message cues and judgments. Journal of Marketing Research, 28, pp. 84-96.

Nichols, J.L. (1982, March). Effectiveness and efficiency of safety belt and child restraint usage programs. DOT/NHTSA Report No. DOT-HS-806-142.

Nolan, M. (1990, June 25). The many faces of Eve: 50-plus. AdWeek's Marketing Week, pp. 45-6.

Office of Disease Prevention and Health Promotion. (1991). Promoting Healthy Diets and Active Lifestyles to Lower-SES Adults Market Research for Public Education. Washington, D.C.: Public Health Service.

Pasick, R.J. \& Wallack, L. (1988-89). Mass media in health promotion: A compilation of expert opinion. Quarterly of Community Health Education, 9, pp. $89-110$.

Perkins, D.D. \& Dunton, S.M. (1987, May). Health risk appraisal and safety belt use. DOT/NHTSA Report No. DOT-HS-807-139, Contract No. DTNH22-85-C-07150. 
Peter D. Hart Associates in conjunction with McHugh \& Hoffman, Inc. (1990). Women, Health \& the Media: Opportunities for the 1990's. Washington, D.C.: Author.

Planek, T.W. \& Fowler R.C. (1971, April). Traffic Accident Problems and Exposure Characteristics of the Aging Driver. Gerontology Journal, 26(2), pp. 224-30.

Popkin, C.L. (1992). Identifying High Risk Driving Behavior in Women. Highway Safety Research Center, University of North Carolina.

(1991, February). Drinking and Driving by Young Females. Accident Analysis and Prevention, 23(1), pp. 37-44.

Public Health Service. (1989, April). Making Health Communication Programs Work: A Planner's Guide. Washington, D.C.: U.S. Department of Health and Human Services.

. (1991, September). PHS Action Plan for Women's Health. Washington, D.C.: U.S. Department of Health and Human Services.

Schechter, C., Vanchieri, D., \& Crofton, C. (1990, May/June). Evaluating women's attitudes and perceptions in developing mammography promotion messages. Public Health Reports, 105, pp. 253-8.

Scott, M. (1986). Future safety and health problems facing working women. Professional Safety, 21, pp. 31-4.

Serafin, R. (1988, May 16). Carmakers step up chase for women. Advertising Age, p. 76.

. \& Strnad, P. (1990, March 26). Advantage: air bags, New Chrysler print ads get specific. Advertising Age, p. 50.

(1991, October 28). GM, Volvo ads push car-safety features, Chrysler air-bag success attracts competition. Advertising Age, p. 52.

. (1989, September 11). Bumper crop of safety issues a challenge. Advertising Age, pp. 5-2.

(1990, April 16). That's no dummy in Chrysler ad, Automakers take safety crash course. Advertising Age, p. 21. 
. \& Horton, C. (1991, June 3). Safety themes aim at boomers, Auto ads follow Volvo, Chrysler lead. Advertising Age, pp. 1, 51.

. (1991, August 5). Pontiac ejects style for virtue. Advertising Age.

Shelly, J.M., Irwig, L.M., Simpson, J.M., \& Macaskill, P. (1991). Evaluation of a mass-media-led campaign to increase Pap smear screening. Health Education Report, 6, pp. 267-77.

The Sherman Group. (1982). Adam and Eve. Unpublished study conducted for the U.S. Equal Opportunity Commission.

Shinar, D. \& Treat, J.R. (1977). Tri-Level study: Modification, Task 3. A Validity Assessment of Police-Reported Accident Data. Final Report. Indiana University Institute for Research in Public Safety, DOT-HS-034-3-535.

Sleet, D.A. (1984). Occupant protection and health promotion. Health Education Quarterly, 11 pp. 109-11.

Staff. (1986, July 14). 'Myths' about women called costly to auto makers. Automotive News, p. 16.

Staff. (1986, August 11). Chrysler outlines needs of women customers. Automotive News, p. E4.

Staff. (1989, April 1). Automobile lib. The Economist, p. 64.

Staff. (1991, November 5). Families pick the winners. Family Circle, p. 46.

Staff. (1991, Summer). 1990 stats show startling drop in child fatalities. Safe Ride News, p. 1.

Steinberg, J. (1988, March 7). Signs point to great reach via outdoors. Advertising Age Special Report: Marketing to Women, p. S-2.

Stewart, J.R. (1972). An Analysis of Annual Milage Self Reported by Renewal Applicants. University of North Carolina, Highway Safety Research Center, HS-021 678.

Stroud, R. (1989, April 3). Chasing car ads: Women's magazines seek fair share. Advertising Age, p. 6.

Stroud, R. (1988, March 7). Papers rise to women's market challenge. Advertising Age Special Report, p. S-3. 
Struckman-Johnson, C.J., Gilliland, R.C., et al. (1990). The effects of fear of AIDS and gender on responses to fear-arousing condom ads. Journal of Applied Social Psychology, 20, pp. 1396-410.

Swinehart, J.W. (1981, June). A descriptive review of selected mass media campaigns on highway safety. DOT/NHTSA Report No. DOT-HS-805-954, Contract No. DOT-HS-9-02295.

Tannen. D. (1990). You Just Don't Understand: Women and Men in Conversation. New York:William Morrow \& Company.

Vegega, M. \& Klein, T.M. (1992, March 20). Trends in alcohol-related traffic fatalities, sex - U.S., 1982-1990. Morbidity and Morality Weekly Report, U.S. Department of Health and Human Services, Public Health Service, 41(11), p. 189.

Vener, A.M. \& Krupka, L.R. (1985). Over-the-counter anorexiant use and perceptions among young adults in Phenylpropanolamine Risks, Benefits and Controversies, J. Morgan (ed.), Praeger, New York, pp. 132-49.

Wallach, V. (1986, September 15). Females play a big part in industry. Advertising Age, p. S-17.

Waller, P.F. \& Reinfurt, D.W. (1973, June). The Who and When of Accident Risk: Can Driver License Programs Provide Countermeasures. North Carolina University, Highway Safety Research Center.

Warren, R.A. \& Simpson, H.M. (1980). Exposure and Alcohol as Risk Factors in the Fatal Nighttime Collisions of Men and Women Drivers. Journal of Safety Research, 12(4), pp. 151-56.

Weber, K. (1975). Men and Women Drivers: A Study of Exposure, Accidents, and Injuries. University of Michigan, Highway Safety Research Institute.

Widen, S. (1974). Night Traffic Accidents, A Review of the Literature. National Swedish Road \& Traffic Research Institute Drotting Kristinas, 56.

Wilson, T. \& Greensmith, J. (1983, June 3). Human Factors, 25(3), pp. 303-12.

Winters, M. (1992, August 21). Women catching up as bad drivers. Washington Times. 
Whipple, T.W. \& Courtney, A.E. (1980). How to portray women in t.v. commercials. Journal of Advertising Research, 20, pp. 53-9.

Wortzel, L.H. \& Frisbee, J.M. (1974). Women's role portrayal preferences in advertisements: An empirical study. Journal of Marketing, 38, pp. 41-6.

Zipkin, A. (1988, March 7). Radio's strength loud and clear. Advertising Age Special Report, p. S-10.

. (1990, October 1). Saturn flies sans air bags. Advertising Age, p. 54.

- (1991, December 9). Last minute news, Chrysler queries FTC on Volvo. Advertising Age, p. 8.

. (1991, July 15). Last minute news, Chrysler touts kids safety seats. Advertising Age, p. 8.

. (1992, August 21). What women really want when buying a car.

Washington Times.

. (1992, May 19). Volkswagen agrees to rehire workers in Mexico. New York Times. 


\section{APPENDIX B}

\section{Experts and Consultants}

B1 List of Experts Consulted or Interviewed

B2 Participant List: General Motors Corporation Meeting

B3 Participant List: Chrysler Corporation Meeting

B4 Participant List: Ford Motor Company Meeting

B-1 


\section{APPENDIX B1}

\section{List of experts consulted or interviewed}

Susan Ackerman, independent consultant, Strategic Marketing and Research, New York

Elaine Arkin, health communication consultant, Alexandria, Virginia

Ken Beck, Research Director, University of Maryland, The Center for Safety Education, College Park, Maryland

Terry Bellicka, public affairs officer, National Heart, Lung, and Blood Institute, Bethesda, Maryland

William DeJong, independent consultant, lectures at Harvard School of Public Health, Cambridge, Massachusetts

Fran Dickman, highway safety specialist, NHTSA Office of Alcohol and State programs, Washington, D.C.

Ellen Eisner, public information officer, Office of Cancer Communications, National Cancer Institute, Bethesda, Maryland

Vicki Freimuth, director, Health Communications Program, University of Maryland, College Park

Ann Grimm, research librarian, University of Michigan Traffic Research Institute, Ann Arbor, Michigan

Ralph Hingson, program evaluator, Massachusetts Saving Lives Program, faculty of Boston University School of Public Health

Nancy Issac, research associate, Harvard School of Public Health

Janine Jason, medical researcher, National AIDS Information and Education Program, Centers for Disease Control, Atlanta, Georgia

Mort LeBow, public affairs officer, American College of Obstetricians and Gynecologists, Washington, D.C.

Steven Lee, Office of Tax Aid and Transportation, American Association of Retired Persons, Washington, D.C. 
Suan Maloney, health communications consultant, Washington, D.C.

Thomas Planek, Director of Research and Statistics for the National Safety Council, editor of The Journal of Traffic Safety

David Sleet, traffic safety expert Professor of the College of Health and Human Services, San Diego, California

Mary Clare Sorrentino, Safe Ride program coordinator, American Academy of Pediatrics, Illinois

James Swinehart, President, Public Communications Resources, Pelham Manor, N.Y.

Lois Timms, research librarian, The Roper Center, Stores, Connecticut

Lawrence Wallack, COMMIT principal investigator, professor, University of California, Berkley 


\title{
APPENDIX B2
}

\section{NHTSA Meeting with General Motors Corporation Regarding \\ Gender Perception Differences to Traffic Safety Messages}

May 4, 1992

\author{
Participant List: \\ Doug Gurin \\ NHTSA \\ Sue Morris \\ S.W. Morris and Co. \\ Lorry L. Purvin \\ Saturn Corporation \\ Kathy Koo \\ S.W. Morris and Co. \\ Bill Scott \\ NHTSA \\ Ken Stack \\ Research and Environmental Staff, GM \\ Milford Bennett \\ Research, GM \\ Amy L. Musary \\ Communications and Marketing Staff, Market Research \\ Center, GM \\ Ron Muratore \\ Communications and Marketing Staff, Advertising \\ Services. GM \\ Patrick G. Walsh \\ Pontiac Motor Division \\ Richard F. Davis \\ Industry-Government Relations Staff. Corporate \\ Relations, GM \\ Leonard Evans \\ Research and Environmental Staff, GM \\ Charies W. Babcock \\ Legal Staff, GM \\ David Viano \\ Research and Environmental Staff, GM \\ Anne F. Ginn \\ Industry-Government Relations Staff. GM
}




\section{APPENDIX B3}

\section{NHTSA Meeting with Chrysler Corporation Regarding \\ Gender Perception Differences to Traffic Safety Messages}

August 18, 1992

\section{Participant List:}

Jesse Blatt

NHTSA

Doug Gurin

NHTSA

Dale Dawkins

Vehicle Compliance and Safety Affairs, Chrysler

Diane Jackson

Marketing Plans, Chrysler Corporation

Marvin Yagen

New Car Sales, Chrysler

Phil Reuschle

Bozell, Inc., Ad Agency for Chrysler

Dave Boswick

Research/International Business Plan, Chrysler

Cindy Frey

JA Product Planning, Chrysler Corporation

Steve Bruyn

Marketing Plans/Cellular Phones

Nicki Kapron

Service and Parts, Females Advisory Committee

Cleo Parker

Bozell, Inc., Ad Agency for Chrysler

Mary Suchara

Corporate Advertising, Chrysler Corporation

Ron Zarowitz

Manager, Car and Truck Safety, Chrysler Corporation

Sue Morris

S.W. Morris and Co.

Kathy Koo

S.W. Morris and Co. 


\section{APPENDIX B4}

NHTSA Meeting with Ford Motor Company Regarding Gender Perception Differences to Traffic Safety Messages

August 19, 1992

\section{Participant List:}

Stephanie Janczak

Kathy Koo

Jesse Blatt

Ron Emmert

Ernie Gresh

Lymam M. Forbes

Mimi VanDermleen

Lee Oliphant

Michael Stando

Tracy Williamson

Doug Gurin

Sue Morris

Jim Vondale
ASO, Safety Regulations and Planning, Ford Motor Co.

S.W. Morris and Co.

NHTSA

Marketing Research. Customer Research. Buyer Research. Buyer Patterns. Advertising Concepts.

Ford Motor Co.

ASO, Vehicle Accident and Statistics. Ford Motor Co.

Design Staff, Ergonomics and Interiors, Ford Motor Co.

Design Center, Ford Motor Co.

Ford Division. Merchandising, New Promotions Area, Marketing Programs

ASO, Safety Regulations and Planning, Ford Motor Co.

ASO, Safety Regulations and Planning, Women's Marketing Committee. Ford Motor Co.

NHTSA

S.W. Morris and Co.

Restraint Litigation. Ford Motor Co. 


\section{APPENDIX C}

Research and Programs Analyzed for Background Review

C1 Table A: Review of Commercial Sector

C2 Table B: Review of Public Sector

C3 Table C: Review of Academia 
Table A: Review of Commercial Sector

\begin{tabular}{|c|c|c|c|}
\hline SOURCE & $\begin{array}{l}\text { GENDER ISSUES } \\
\text { STUDIED OR } \\
\text { CONSIDERED }\end{array}$ & $\begin{array}{l}\text { TARGETS MARKET } \\
\text { BY GENI)ER }\end{array}$ & $\begin{array}{l}\text { USEFUL FOR } \\
\text { FOCUS GROUP } \\
\text { PLANNING }\end{array}$ \\
\hline Condé Nast Publications & $\begin{array}{l}\text { No, women only } \\
\text { studied }\end{array}$ & $\mathrm{n} / \mathbf{a}$ & Yes \\
\hline American Demographics & $\begin{array}{l}\text { Yes, differences in } \\
\text { habits and trends }\end{array}$ & $n / a$ & Yes \\
\hline Auto Manufacturers & & & Yes \\
\hline BMW & Yes & No & \\
\hline Chevrolet & Yes & Has in past & \\
\hline Ford & Yes & Has in past & \\
\hline Honda & Yes & Has in past & \\
\hline Hyundai & Yes & Yes & \\
\hline Mercedes-Benz & Yes & No & \\
\hline Toyota & Yes & Has in past & \\
\hline Tobacco Industry & Yes & $\begin{array}{l}\text { Yes, often with } \\
\text { stereotypes }\end{array}$ & Yes \\
\hline
\end{tabular}




\section{Table B: Review of Public Sector}

\begin{tabular}{|c|c|c|c|}
\hline SOURCE & $\begin{array}{l}\text { GENDER DIFFERENCES } \\
\text { STUDIED }\end{array}$ & $\begin{array}{l}\text { DIFFERENCES } \\
\text { FOUND }\end{array}$ & $\begin{array}{l}\text { USEFUL FOR FOCUS } \\
\text { GROUP PLANNING }\end{array}$ \\
\hline \multicolumn{4}{|l|}{ Traffic Safety } \\
\hline \multirow{6}{*}{$\begin{array}{l}\text { D. Sled (safety expert) } \\
\text { Nall. Safey Council } \\
\text { UMTRJ } \\
\text { Center for Safety Education } \\
\text { AAA } \\
\text { IIHS }\end{array}$} & No & 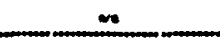 & $N_{0}$ \\
\hline & No & $m$ & $N_{0}$ \\
\hline & No & $\mathbf{m}$ & No \\
\hline & $N_{0}$ & $\alpha$ & No \\
\hline & No & $\omega$ & No \\
\hline & $N_{0}$ & $\omega$ & $N_{*}$ \\
\hline \multirow{3}{*}{$\begin{array}{l}\text { Harvard School of Public Health } \\
\text { Frienda campaign evaluation } \\
\text { Drinking and driving PSAs }\end{array}$} & & & \\
\hline & Fuare study & we & $Y e$ \\
\hline & Yea & No onduntion & You \\
\hline $\begin{array}{l}\text { American Academy of Pediatrics } \\
\text { Child safety seats }\end{array}$ & No & $\mathbf{a} / \mathbf{a}$ & No \\
\hline $\begin{array}{l}\text { American College of OB/GYN's } \\
\text { (seatbelts for pregnant women) }\end{array}$ & No & a/e & Yes \\
\hline \multicolumn{4}{|l|}{$\begin{array}{l}\text { Other Public Heallh } \\
\text { Studies/ Programs }\end{array}$} \\
\hline $\begin{array}{l}\text { Freimuth } \\
\text { (health communications exper) }\end{array}$ & Yea & Yee & $Y=$ \\
\hline $\begin{array}{l}\text { Hart Associates } \\
\text { (health in formation survey) }\end{array}$ & No, womes coly & w/e & $Y \infty$ \\
\hline $\begin{array}{l}\text { Hearst Corporation } \\
\text { (health information survey) }\end{array}$ & No, wame conly & w/ & Yo \\
\hline $\begin{array}{l}\text { Spilman } \\
\text { (worksite health activities) }\end{array}$ & Yea & YeA & Ye \\
\hline \multirow{6}{*}{$\begin{array}{l}\text { Natl. Cancer Institute } \\
\text { Johnson (survey of women) } \\
\text { Cancer Information Service } \\
\text { Colon cancer campaign } \\
\text { Smoking cessation } \\
\text { Breast and cervical cancer }\end{array}$} & & & \\
\hline & No. wome only & $2 / 2$ & Yee \\
\hline & No, wowencenty & $a / 2$ & Ye \\
\hline & Yea. informally & Yea & Ya \\
\hline & No & $D / \mathbf{E}$ & No \\
\hline & No. women cally & n/: & $Y=$ \\
\hline \multirow{3}{*}{$\begin{array}{l}\text { Natl. Heart, Lung, and Blood Inst. } \\
\text { High blood pressure program } \\
\text { Cholesterol education program }\end{array}$} & & & \\
\hline & Yea & Yea & Yea \\
\hline & No & a/a & Yea \\
\hline \multirow{2}{*}{$\begin{array}{l}\text { AIDS Prevention Studies } \\
\text { Centers for Disease Control } \\
\text { (videotapea) }\end{array}$} & & & \\
\hline & loformally & $\sim$ & Yea \\
\hline \multirow{2}{*}{$\begin{array}{l}\text { Struckman-Johnson study } \\
\text { (condoms) } \\
\text { Kyes study } \\
\text { (condoms) }\end{array}$} & Ye & Ye & $Y \infty$ \\
\hline & Yes & Ye & You \\
\hline $\begin{array}{l}\text { Office of Disease Prevention and Health } \\
\text { Promotion } \\
\text { (high-risk adults) }\end{array}$ & Ioformelly & No & Ye \\
\hline \multirow{3}{*}{$\begin{array}{l}\text { American Academy of Pediatrics } \\
\text { Childhood immunization } \\
\text { Safe handling of fire-arms }\end{array}$} & & & \\
\hline & No & $n / \mathbf{m}$ & Yem \\
\hline & No & $\mathrm{a} / \mathbf{2}$ & Yea \\
\hline
\end{tabular}




\section{APPENDIX C3}

\section{Table C: Review of Academia}

\begin{tabular}{||l|l|c|}
\hline $\begin{array}{l}\text { SOURCE } \\
\text { (description) }\end{array}$ & $\begin{array}{l}\text { GENDER DIFFERENCES } \\
\text { STUDIED/FOUND }\end{array}$ & $\begin{array}{c}\text { USEFUL FOR FOCUS } \\
\text { GROUP PLANNING }\end{array}$ \\
\hline $\begin{array}{c}\text { Bellizzi } \\
\text { (car care ad testing) }\end{array}$ & Both genders studied / Yes \\
\hline $\begin{array}{l}\text { Carli } \\
\text { (interaction style } \\
\text { and influence) }\end{array}$ & Both genders studied / Yes & No \\
\hline $\begin{array}{c}\text { DuBrin } \\
\text { (interaction style } \\
\text { and influence) }\end{array}$ & Both genders studied / Yes & No \\
\hline $\begin{array}{l}\text { Jaffe } \\
\text { (financial services } \\
\text { to women) }\end{array}$ & Both genders studied / Yes & Yes \\
\hline $\begin{array}{c}\text { Gould } \\
\text { (self-perception and } \\
\text { ad influence) }\end{array}$ & Both genders studied / Yes & Slight \\
\hline $\begin{array}{l}\text { Lammers } \\
\text { (self-perception and } \\
\text { humorous ads) }\end{array}$ & Both genders studied / Yes & Slight \\
\hline
\end{tabular}




\section{APPENDIX D}

Focus Group Materials
D1 Participant Screener
D2 Moderator's Guide
D3 Sample PSA Rating Form
D4 Participant Information Sheet
D5 Participant Information Sheet/ Selected Response Tallies 


\section{APPENDIX D1 \\ S.W.MORRISGCOMPANYNC.}

\section{PARTICIPANT SCREENER}

\section{GENDER}

Focus Groups

National Highway Transportation Safety Administration

FORMAT: 8 Focus Groups (4 male, 4 female)

\section{Introduction}

Hello, I'm We're holding group discussions on traffic safety issues. These discussions last approximately one and a half hours. I'd like to ask you a few questions to see if you will be able to participate. The incentive for participation is $\$ 30$. Refreshments will also be served.

1. Indicate gender of participant:

Male

Female

Terminate if quota is met.

(Keep running tally: quota is to recruit 12 participants for four groups each of men and women.)

2. What is your age?

Under 25

Terminate: Thank you but we are recruiting individuals over 25 at this time.
$25-39$
(Recruit 2 groups male, 2 groups female)
$40-59$
(Recruit 2 groups male, 2 groups female)

60 \& Over

Terminate: Thank you but we are recruiting individuals between the ages of 25 and 60 at this time. 
3. Are you a licensed driver?

Yes

No __ Terminate: Thank you but we are only recruiting licensed drivers at this time.

4. Approximately how many miles do you drive in a year?

For Males:

10,000 miles or less

Terminate: Thank you but we are recruiting individuals who drive over 10,000 miles per year.

More than 10,000

For Females:

7,000 miles or less

Terminate: Thank you but we are recruiting individuals who drive over 7,000 miles per year.

More than 7,000

5. Are you in an advertising or marketing research profession?

No Yes

Terminate: Thank you but we are not recruiting individuals who work in these areas of expertise.

6. What is your marital status?

Married

Single

(Keep running tally: recruit a minimum

Divorced of four in each group of marrieds/singles.)

Widowed 
7. How many children or other dependents live at home with you?

None

Number What are their ages?

(Keep tally: recruit a minimum of four in each group with at least one dependent living at home.)

8. What is your level of education? What is the last year of school you completed?

Less than a high school diploma Terminate: Thank you but we are recruiting high school graduates at this time.

High school diploma/GED

Some college

College degree

Advanced degree

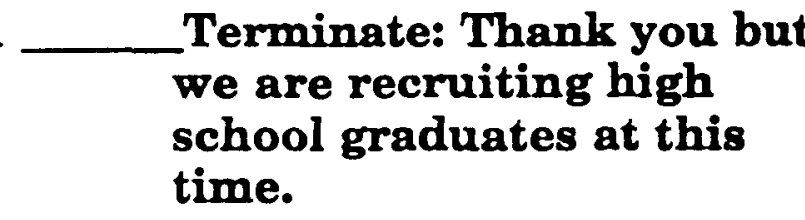


For Females Ages 25-39:

Tuesday, October 27 at $8 \mathrm{pm}$

Wednesday, November 4 at 6 pm

For Females Ages 40-59:

Wednesday, October 28 at 8 pm

Thursday, November 5 at $6 \mathrm{pm}$

10. May I have your name, address, and a daytime and evening phone number where you can be reached?

Name:

Phone: Day $($ )

Evening

Address:

We are glad that you'll be joining us. We will see you on the (Confirmed DATE from above). In the meantime, we will send you a confirmation letter and directions and please call me if you have any questions.

Recruiter Please Note: We would like to target at least two non-white participants for participation in each group. 


\section{APPENDIX D2 \\ S.W.MORRISGCOMPANYNC.}

\section{Moderator's Guide}

\section{Introduction}
A. 90 minutes.
B. Session is recorded -- need to talk one at a time.
C. Everyone participates.
D. No right/wrong answers -- need opinions.

\section{Warmup}

A. Name, location of residence.

B. Ask participants to describe how they feel about their commute to work and home.

(Probe: Is your commute relatively easy/relaxing or do you encounter some problems?)

\section{General Driving Issues/Traffic Safety}

A. Everyone has described their feelings about their commute. Now, I'd like to ask generally,

1. What is driving like for you?

(Probe: Is it something you mostly enjoy, find fun and look forward to? Is it something you just put up with or endure because you can't avoid it?)

2. Has your attitude toward driving changed over the last few years? Do you think other drivers' attitudes have changed? Do you find drivers being more courteous, more impatient, more aggressive? Any other changes you've noticed? 
B. What driving mistakes or traffic violations do you see other motorists make most often?

C. Surveys have shown that almost everyone thinks he or she is a betterthan-average driver, but we all make mistakes or violate traffic laws from time to time.

What kinds of risky actions do you personally take most often?

(Permit participants to mention as many or as few as they feel relevant. The following list is for prompts, if needed).

- Driving 10-15 mph or more over the speed limit.

- Turning left in front of close oncoming traffic.

- Driving soon after drinking.

- Following another car too closely.

- Not paying enough attention to the road because of distractions.

(Probe: Radio/tape playing, make-up application, passenger behaviors, other stresses.)

\section{Reactions to Specific Traffic Safety Messages}

A. Think of a few ads on highway safety topics that you remember from TV, radio, magazines or newspapers. Let's try to list about five, preferably dealing with several different topics. (Summertime Blues...)

B. Why do you remember these particular ads?

C. We're going to spend most of our remaining time discussing several ads that deal with three highway safety topics. I'm passing around some forms so that each of you can put down your personal reactions to the ads before we talk about them. I'll collect these forms after the discussion. 


\section{(Distribute rating form)}

(Show the selected ads, one at a time, allowing a minute or so after each one for people to complete a rating form. For each, ask the following questions.)

1. Was there anything about the ad that you particularly liked or attracted your attention? Why?

(Probe: Particular feelings.)

2. Was there anything you particularly disliked/turned you off? Why?

3. Would you be likely to drive any differently as a result of seeing/hearing this ad? Why?

4. What would you say is the main message or idea that this ad is trying to get across? Any other messages?

5. Do you agree with the message?

6. Do you think that the ad would work better with men, or with women, or that both would react to it in about the same way? Why do you say that?

7. Moderator instruction: Tailor this question to the topic of the specific ad you are discussing, as well as the sex of the group.)

a. If you wanted to influence the willingness of men/women to wear seatbelts, what changes would you make? Why?

b. If you wanted to influence men/women not to drink and drive, what changes would you make? Why?

c. If you wanted to influence men/women not to speed, what changes would you make? Why? 


\section{Summary of Discussion of Gender Differences}

A. Thinking back to all of your comments about making various ads more effective, can we come up with any general ideas or principles that apply across different safety topics That is, can you think of some advice that producers could use in doing highway safety ads, if the topic was speeding, drinking and driving or wearing seat belts?

1. What themes and appeals work best? (List those used in spots shown.)

(Protect your life and that of others, avoid arrest, save financial costs, avoid injury, "everyone's doing it" approach, personal and moral responsibility.)

2. What characteristics should spokespersons/characters in ads have? Gender, Age, Social role portrayed: Authority figure, caregiver/parent, victim/survivor, friend, etc.)

\section{Close}

(Pass out participant information sheet and ask participants to take a few moments to fill it out.)

Thank everyone for coming and explain to them how their reimbursement will be given to them as they leave. 


\section{APPENDIX D3}

\section{Public Service Announcement Rating Form}

\section{Spot \#1: The Next 60 Minutes of Your Life}

Please make a mark on one of the blanks below for each question:

Would you say that the ad:

Conveyed a message that was:

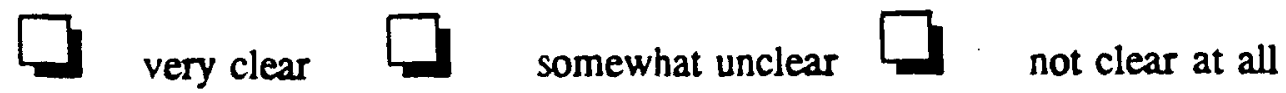

Conveyed a message that was:

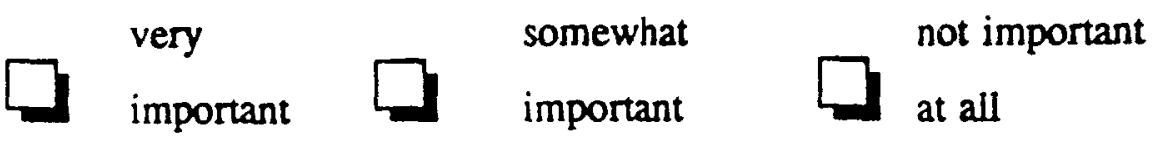

Was relevant to you personally?
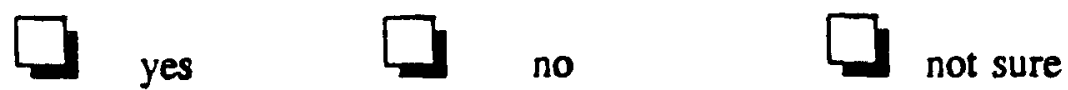

Was intended mostly for men, mostly for women, or for both sexes?

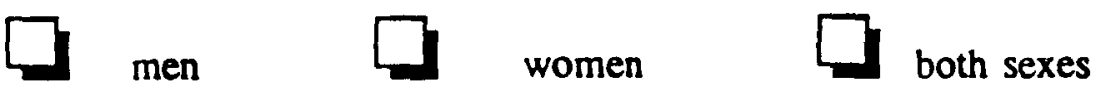

Was intended mostly for people in what age range?

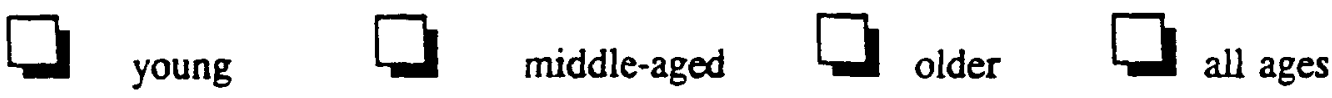

Conveyed useful information?

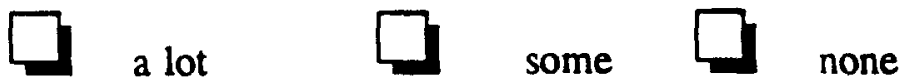

Told you something that you didn't already know?

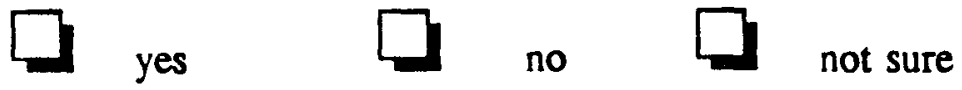




\section{APPENDIX D4 \\ Participant Information Sheet}

1. What is your age?

2. What is your occupation?

b. Are you employed full time outside the home?

No $\square$ Yes $\square$

If yes, what is your commuting distance per day?

3. When do you do most of your driving?

Morning/Evening Rush $\square$ Other Daytime $\square$ Nights $\square$

b. How would you describe the traffic you drive in most often?
Light
Light to Medium
Medium to Heavy
$\square$ Heavy
$\square$

4. What are the ages of your dependents who currently reside with you? Ages No Dependents

5. W. What size vehicle do you drive most often?

Sub-compact
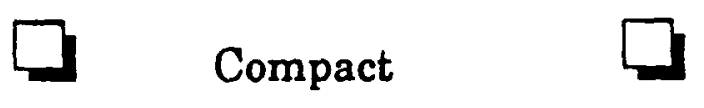

Mid-size Car
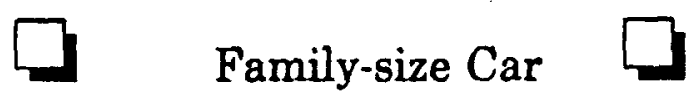

b. What is the make, model and year of the above vehicle? Make Model Year 
c. What is the vehicle type?

Sedan $\square$ Station Wagon $\square$ Minivan $\square$

Pickup Truck $\square$ Other 4-wheel Drive Vehicle $\square$

Sports Car $\square$ Other: (describe)

6. W. When was the last time you bought a new car?

b. When was the last time you bought a used car?

7. How often do you wear a seatbelt when you drive?
Always
$\square$
Most of the time
$\square$
Sometimes
$\square$ Never $\square$

8. Would you say you take more risks than the average driver, take typical risks, or that you are more cautious than the average driver?

More risky $\square$ Typical $\square$ More cautious $\square$

9. How often do you drive more than $15 \mathrm{mph}$ above the posted speed limit?

Very often
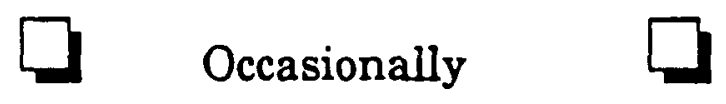

Seldom
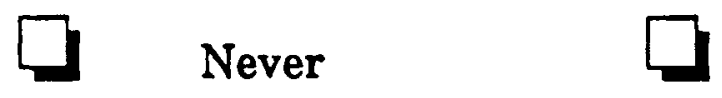

10. How often do you drive within an hour of having one or more alcoholic drinks?

Very often
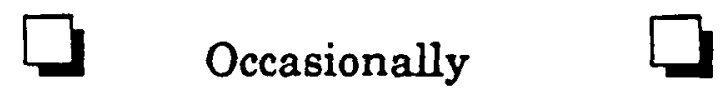

Seldom
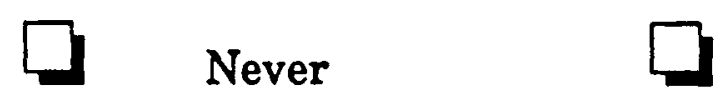
11. a. Have you been stopped or ticketed for a traffic violation in the past 3 years?

No $\square$ Yes $\square$ If so, for what?

b. Have you had a police - reported traffic accident in the last 3 years?

No $\square \quad$ Yes $\square$

12. Have you ever signalled your annoyance/impatience with another driver's slow or bad driving?

No $\square$ Yes $\square$ If so, how? 
PARTICIPANT INFORMATION SHEET/SELECTED RESPONSE TALLIES

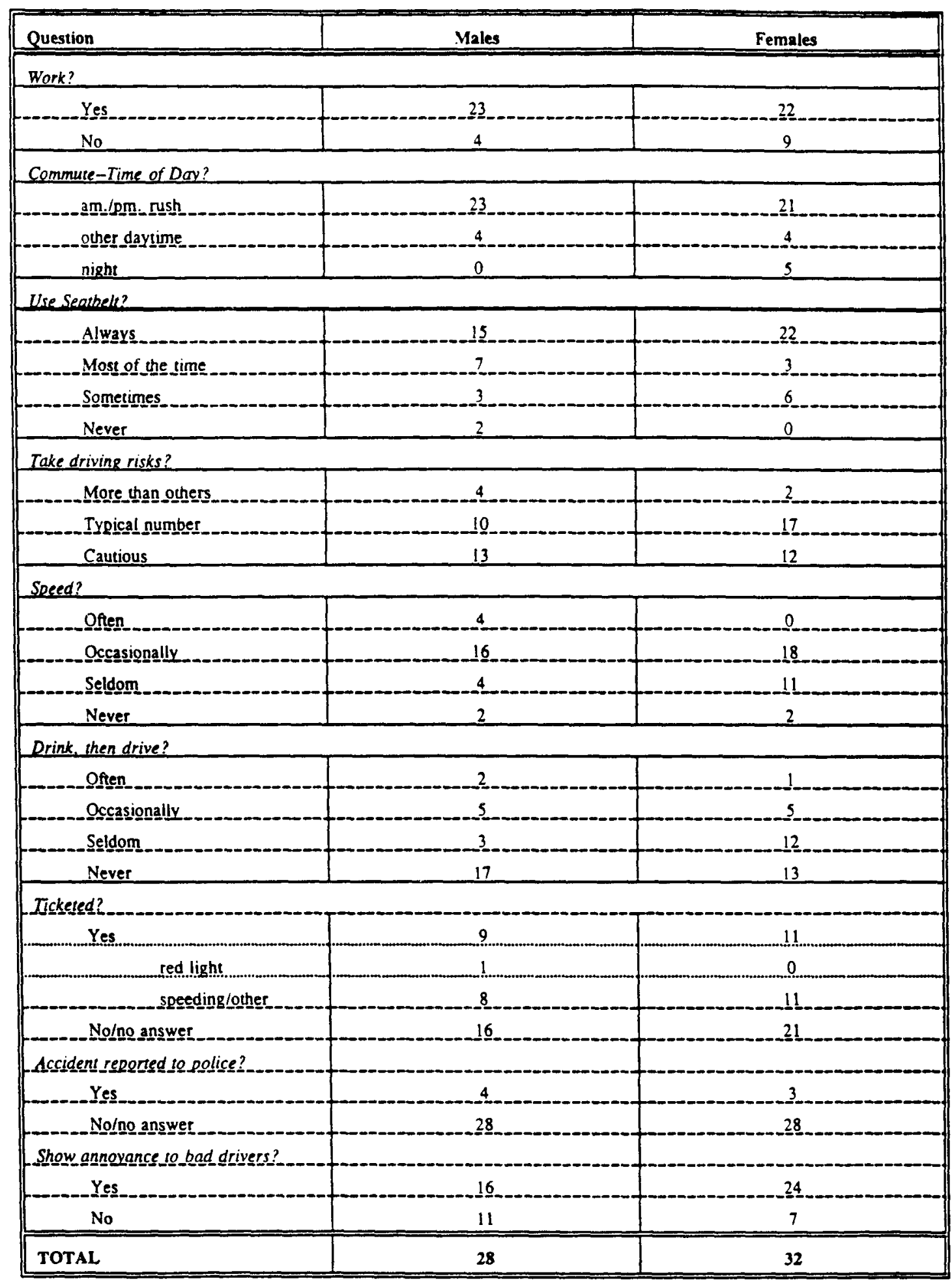

NOTE: Numbers may not equal total because of participants who did not respond or who gave more than one response. 